\title{
التطبيقات الحديثة للنقل متعدد الوسائط
}

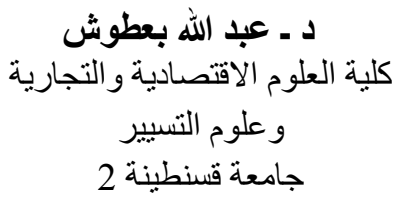

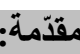

ساهمت التغيرات، التي أفرزتها

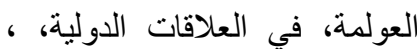

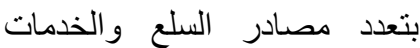

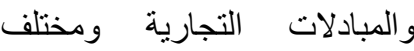

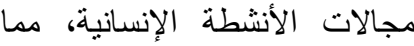

أدى إلى تحقيق نمو كبير في الإنيطية

التجارة العالمية وانسيابها عبر لعبر

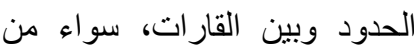

خلال مختلف مراكز الإنتاج

الدولية، أو الأسواق الداخلية

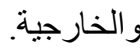

هذا ما أدى بدوره، إلى الزيادة في

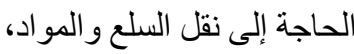

أفرزت ظاهرة العولمة، نغيرات كبيرة في العلاقات الدولية، و سمحت بفتح

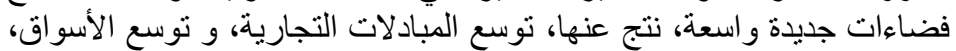

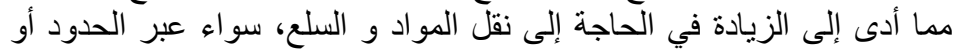

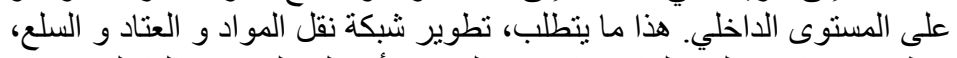

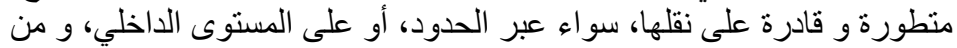

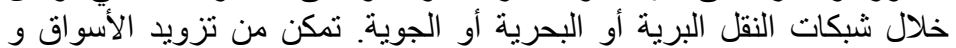

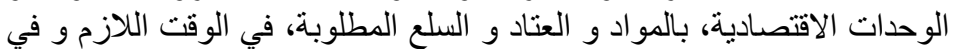

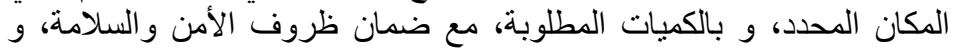
بأدنى التكليف.إن هذه الثروط، لا بمكن تحقيقها، إلا بوجود شبان شبكة نقل، متعدد

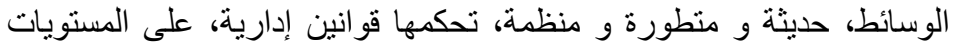

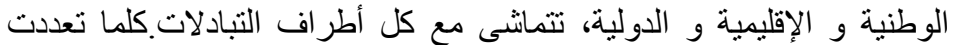

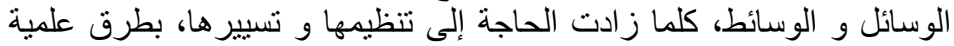

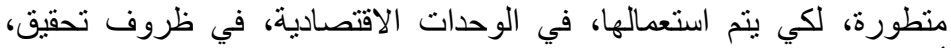

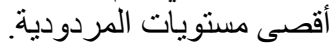

الكلمات المفتاحية: الوحدات الاقتصائة الودية، النقل متعدد الوسائط، تحريك المواد،

نشاط النقل، شبكة النقل

\section{Résumé:}

Le phénomène de la mondialisation a entrainé des changements profonds au niveau des relations économiques internationales ce qui a permis l'ouverture de nouveaux espaces très vastes dans le domaine des échanges commerciaux et l'élargissement des marches. Ceci a rendu le besoin de transporter les biens et le matériel, que ce soit à travers les frontières ou au niveau local, de plus en plus pressant. Ce qui nécessite le développement d'un réseau de transport moderne capable d'assurer les opérations de transport que ce soit au niveau national ou international ou par le moyen du transport terrestre ou maritime ou aérien et d'approvisionner les marches et les unités économiques en produits et matériaux nécessaires au moment et à l'endroit voulu et en quantités nécessaires tout en assurant la sécurité et le transport dans de bonnes conditions et avec un moindre cout.

Ces conditions, ne peuvent être réalisées que par l'existence d'un réseau de transport complexe développé, moderne et organise, géré par des règles nationales, régionales et internationales préservant les intérêts de tous les acteurs.

Plus, les moyens de transport se développent et deviennent complexes, plus il devient nécessaire de développer de nouvelles méthodes d'organisation pour une gestion scientifique permettant leurs utilisation dans les unités économiques en réalisant le plus haut niveau de rendement.

Mots clés : Unités économiques, transport multimodal, manipulation, activité de transport, réseau de transport.

2016 جامعة الإخوة منتوري قسنطينة، الجز ائر (C) 


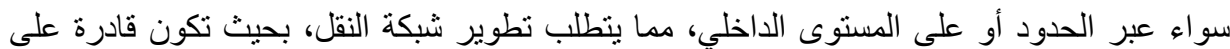

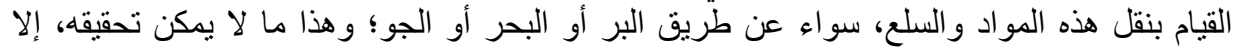

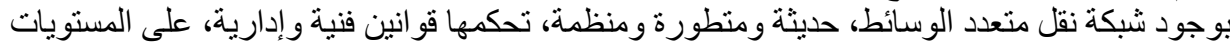

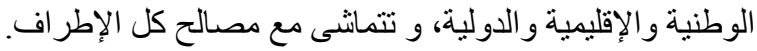

كلما تعددت الوسائل و الوسائط، كلما زادت الحاجة إلى تتظيمها و تسيير ها بطرق علمية منطورة، لكي

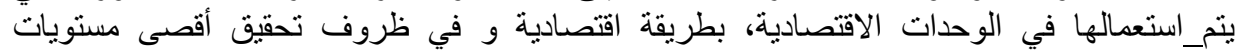

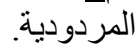

و تتمحور إثكالية البث، حول التساؤل التالي:" كيف غيبرت، التطبيقات الحليثة، مفهوم النقل متعدد

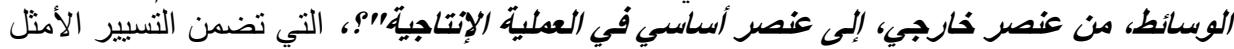
للتوليفة المتكونة من ( "كمية الإنتاج، ومو اعيد التسليم و التكاليف").

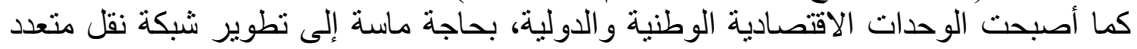

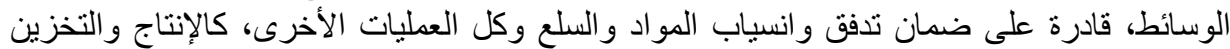

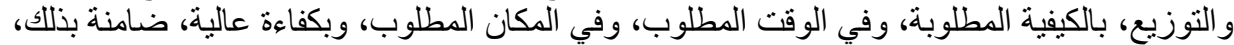

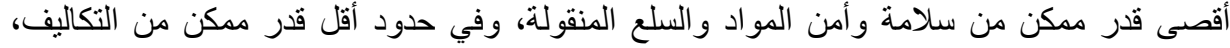

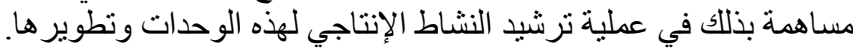

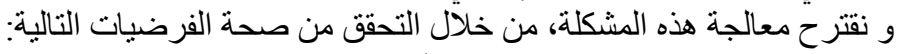

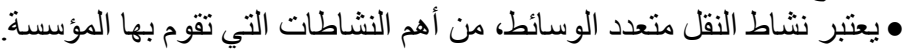

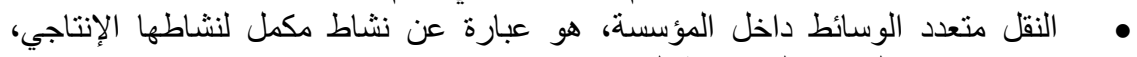

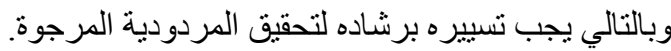
تركيز الاهتمام، نحو تحقيق تكامل وسائط النقل، على المستوى الوطني و الدولي، وذلك نتيجة لتنوع الوسائط وتعقدها.

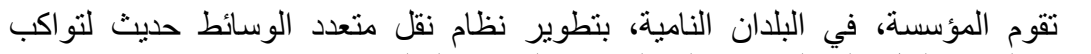

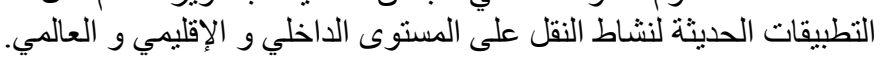

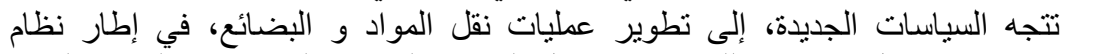

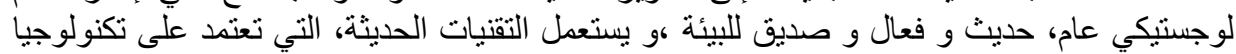

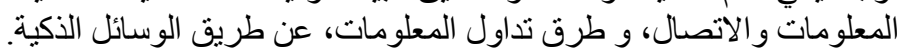

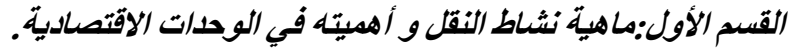
1

إن كلمة النقل، تعني عملية تغيير مكان الأفراد أو مختلف المو ادو و السلع أو العتاد، على مدى المسافة التي

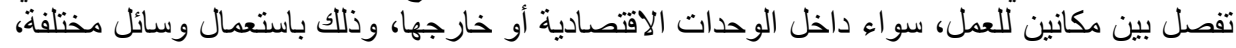

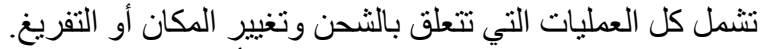

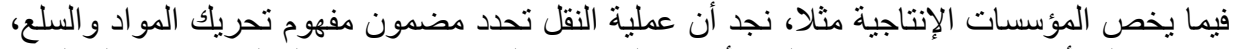

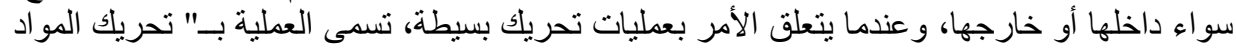

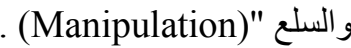
ويمكن إبراز مختلف عمليات النقل المستعطلة في الوحدات الاقتصادية، وفقا للثكل البياني التالي: الثكل رقم (1): مختلف عمليات النقل المستعملة في الوحدات الاقتصادية و الرموز الموافقة لها. 


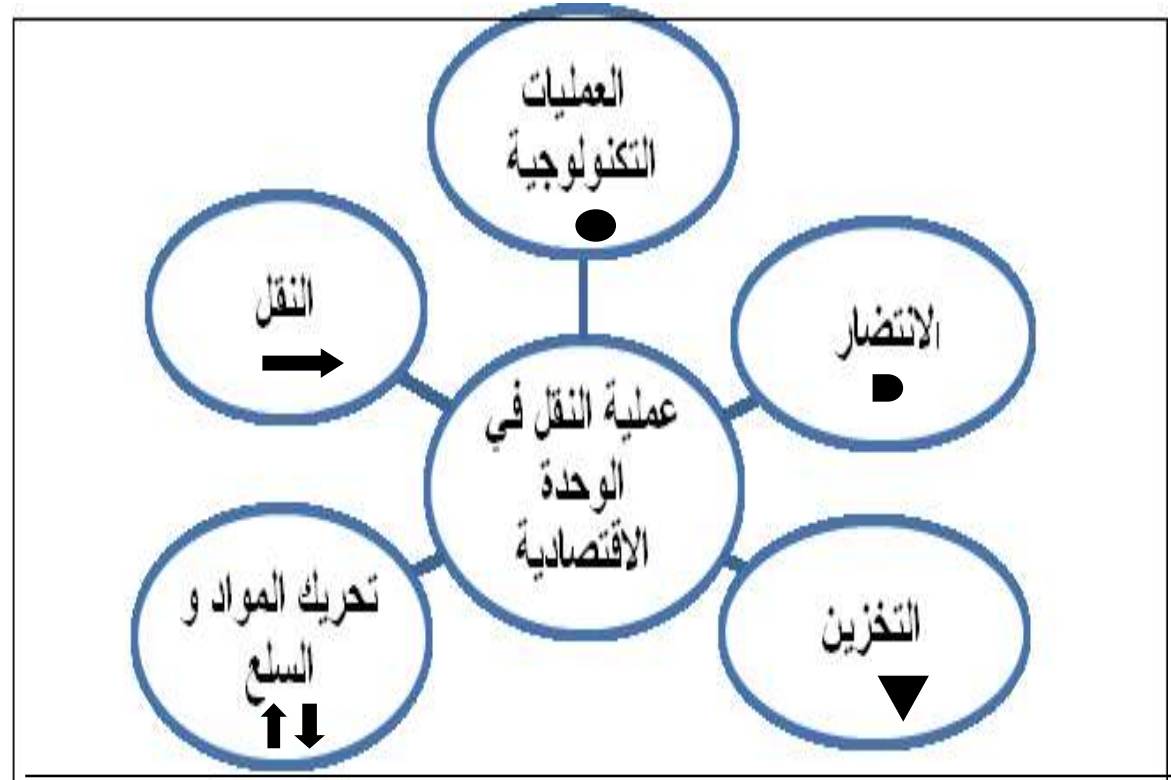

$$
\text { المصدر:.الشكل من تصميم الباحث. }
$$

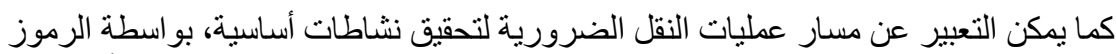

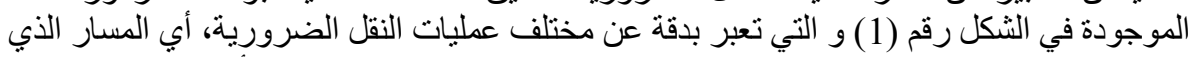

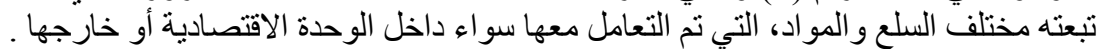

الثكل رقم (2) التالي، بمثل مقطع من العمليات التي تمت في الوحدة الاقتصادية، وذلك باستعمال

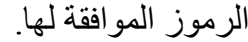

الثكل رقم (2): مقطع من العمليات التي تمت في الوحدة الاقتصادية وذلك باستعمال الرموز الموافقة

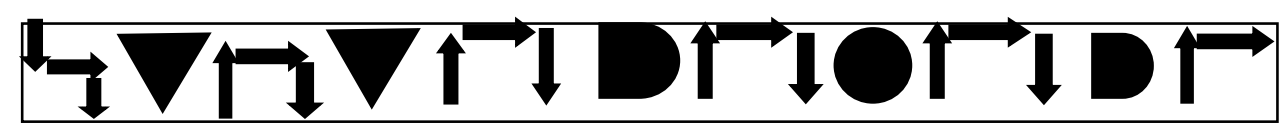

$$
\text { المصدر: من تصميم الباحث }
$$

الثكل رقم (2) عبارة عن تمثيل بياني لتتابع عمليات المناولة و النقل (تحريك المو اد و السلع) و التخزين و الانتظار الضرورية لتحقيق العمليات الأساسية في الوحدة الإنتاجية.

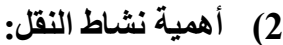

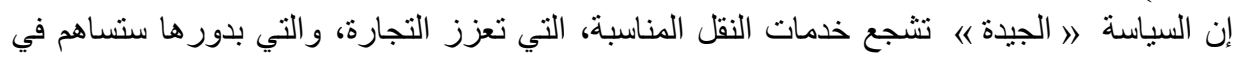

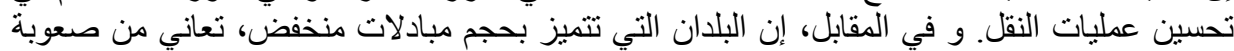

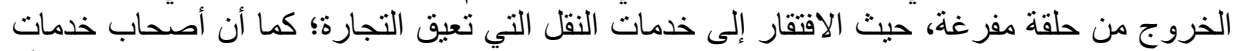

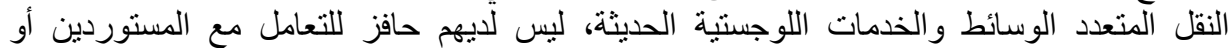
المصدرين المحليين في هذه البلدان، الأمر الذي يؤدي إلى ارتفاع تكاليف المعاملات. 
في العقود الأخيرة، العولمة و الابتكار ات التكنولوجية غيرت طريقة التعامل مع الإنتاج و التجارة و النقل، سو اء في البلدان المتقدمة أو في البلدان النامية.

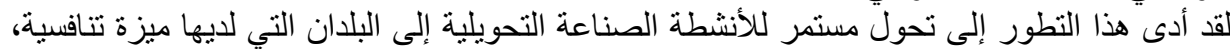

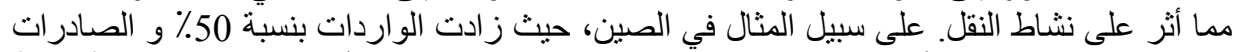

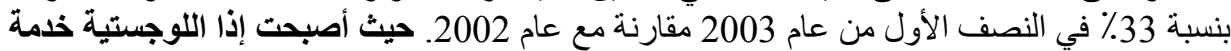

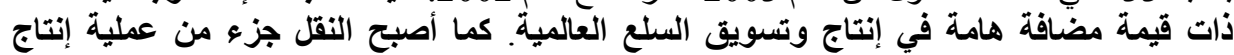

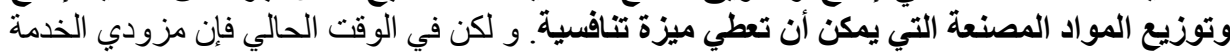

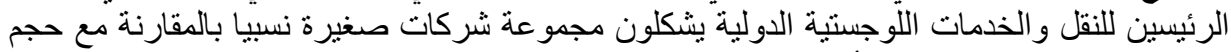
المبادلات الدولية، و يمكن ذكر أبرز الثركات:

،( MaerskSealand, Mediterranean Shipping Company, P\&O Nedlloyd, etc.)

( Corporation, P\&O Ports, etc.) (Hutchinson Port Holdings, Port of Singapore) ومقدمي الخدمات اللوجستية. (Kuehne \& Nagel, Panalpina, etc.).

و بالتالي فإن السوق العالمية تقدم فرصا قليلة للقادمين الجدد، إذا يجب التركيز على الخدمات المحلية

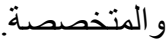

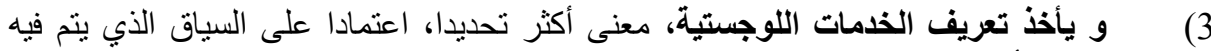

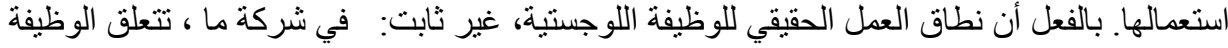

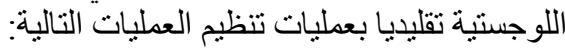

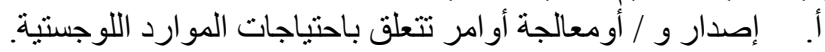

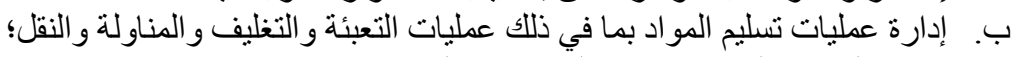

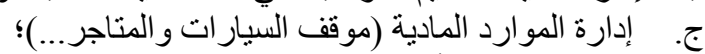

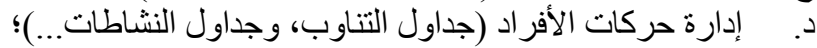

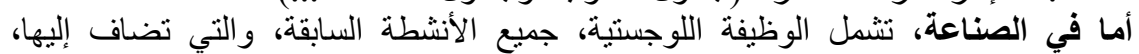

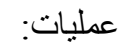

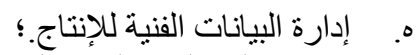

و. تخطيط المنطلبات المادية للإنتاج.

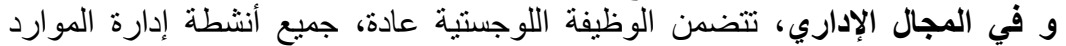

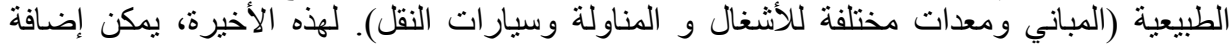
"الخدمات العامة" (الصبانة الصغيرة و الصيانة و الأمن ...).

و من الملاحظ، أنه في أغلبية المنظمات، نم فصل الأنشطة المتعلقة بالأنشطة اللوجستية إلى الى

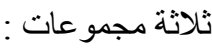

1. الأنشطة المنصلة مبانشرة بالإنتاج الداخلي للسلع و الخدمات (المشتريات و التصنيع و التوزيع و المو اد المعادة)

2. أنشطة إدارة وسائل نقل الأشخاص أو البضائع إلى الثركة الخارجية

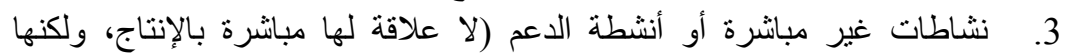

ضرورية لتحقيق العطليات الإنتاجية). (1)

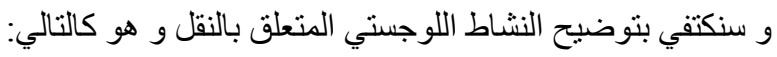

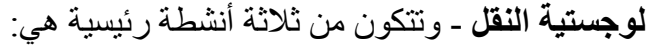
تحديد شبكات النقل وتخطيط النقل و إدارة حظيرة المركبات تحديد شبكات النقل:

و ينعلق الأمر بتحليل شبكات النقل المختلفة واختبار أفضل عرض على على أساس التكلفة والوقت

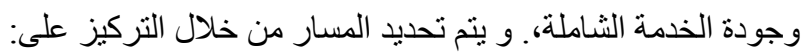


طريقة تسليم البضائع (البحرية و الجوية و السكك الحديدية و الطرق و النقل المتعدد الوسائط)؛

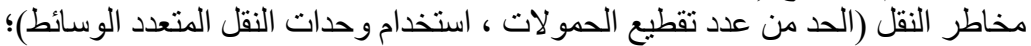

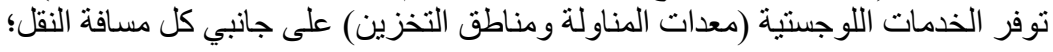

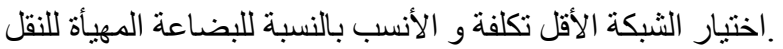

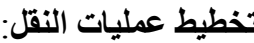

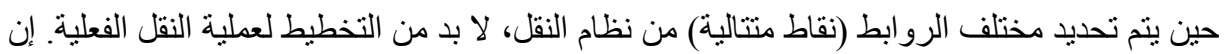
عملية تخطيط النقل تحتل مكانا هاما في إدارة جولات تسليم البضائ النيأع و النقل بين المصانع أو بين

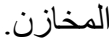

و تتمثل عملية تخطيط النقل في توقع و تحديد في الوقت المناسب، كميات، و أماكن السلع وتواريخ نقلها، و هذا ما بسمح بالأداء المسبق للتعديلات وتحقيق التوازنات اللازمة أخذا بعين الاعتبار القدرات الحقات الحقيقية للنقل المتوفرة و كذا نسبة تحميل الثاحنات.

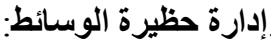

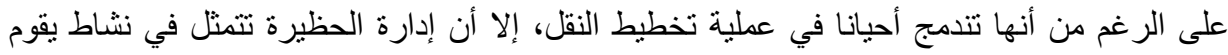

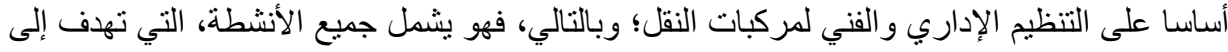

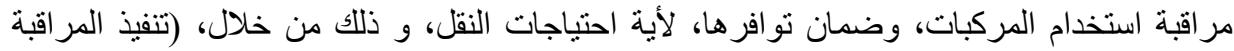

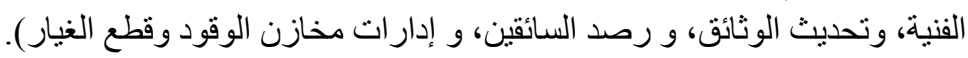

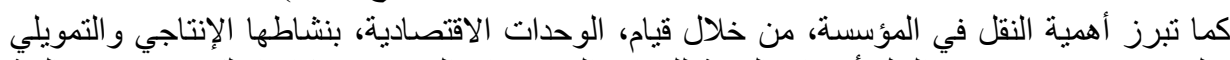

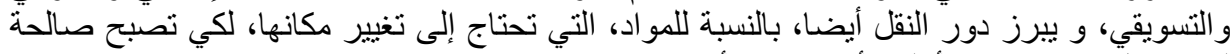

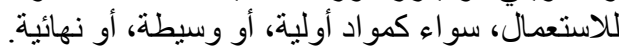

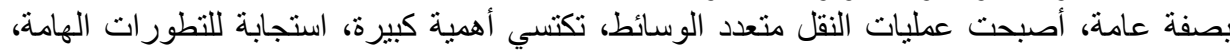

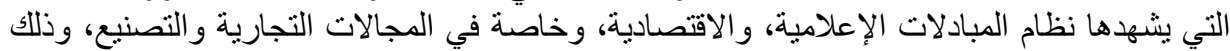

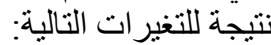

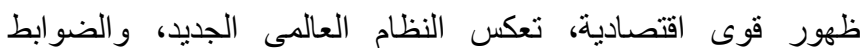
$(1$

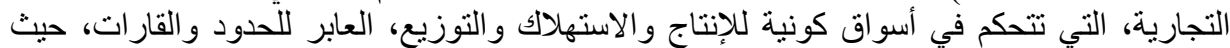
أصبحت هذه الوظائف الآساسية للوحدات الاقتصادية، تكتسي طابعا دوليا.

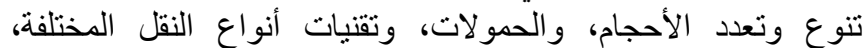

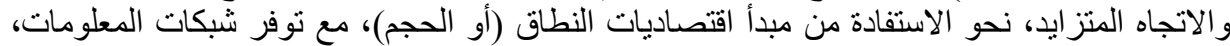

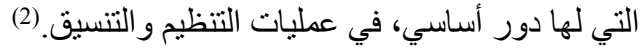

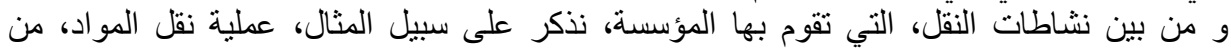

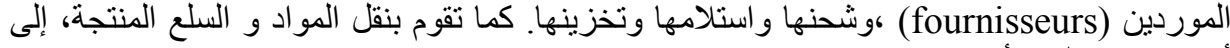

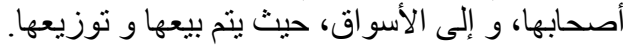

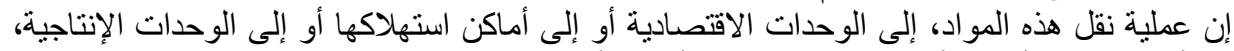

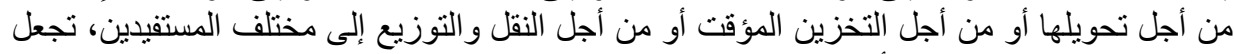

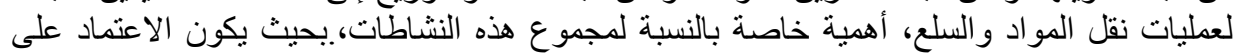

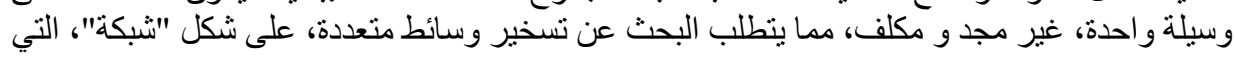
تمكن من القيام بعمليات النقل بطريقة متكاملة. 


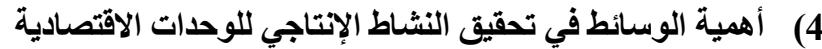

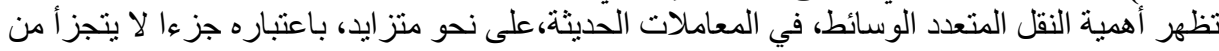

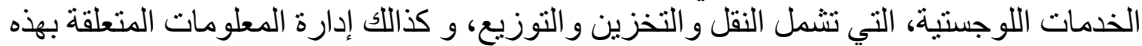
الوظائف. و تكمن أهمية هذا "المنهج المتكامل"، في عملية تجميع تحت عنوان "الخدمات اللوجستية"، ثلاث

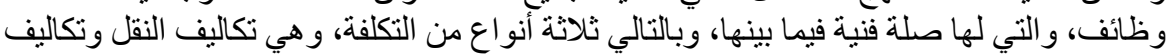
المناولة / التخزين و التكاليف الإدارية.

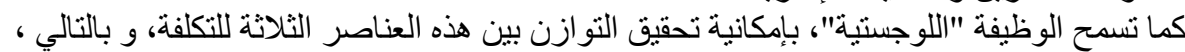

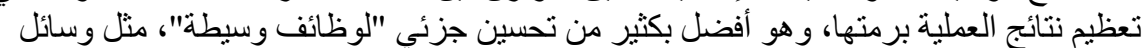

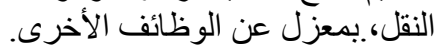

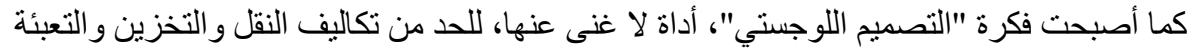

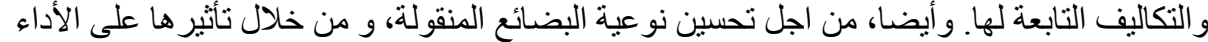
و القدرة على المنافسة للشركات المعنية.

من اجل تحقيق عمليات النقل الداخلية للوحدات الاقتصادية، تستعل مجموعة معقدة من الوسائط أ-ـ/ عناد متنقل وتصنف كالآتي:

$$
\text { ب- بـ/ ميكانزمات (mécanismes) }
$$

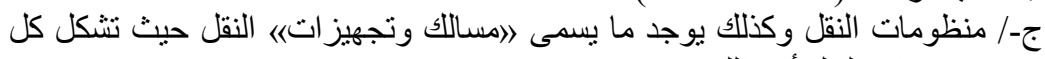

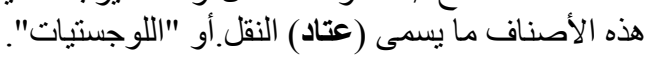
إن التسبير الاقتصادي لعمليات النقل داخل الوحدات الإنيات الاقتصادية، يكتسي أهمية اقتصادية كبيرة، بحيث

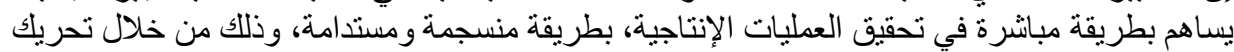

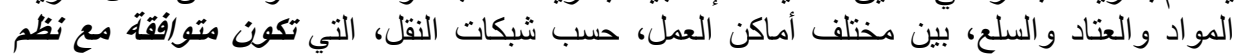
الإنتاج، .مما يؤدي إلى تخفيض التئ حجم التكاليف.

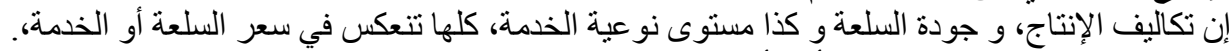

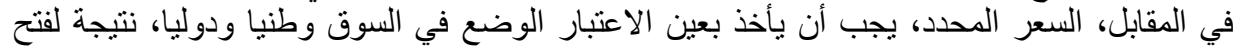

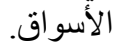

و لتحقيق صفقة تجارية، يجب على البائع، أن يأخذ في الاعتبار، ثلاث وظائف أساسية. (1) وظيفة

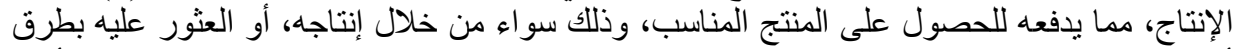

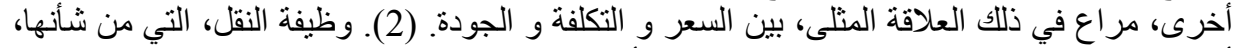

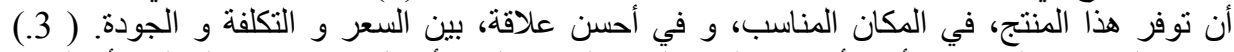
وظيفة التخزين، التي من شأنها، أن تبقي المنتج لحين الحاجة إليه، بأفضل مستوى من التكاليف أو السعر

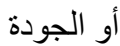

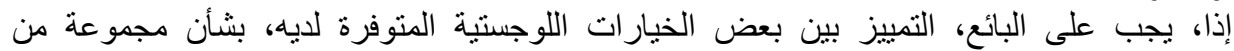

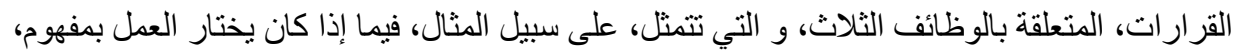

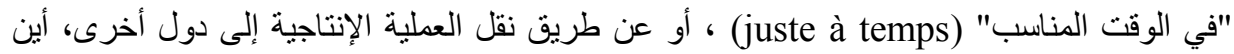

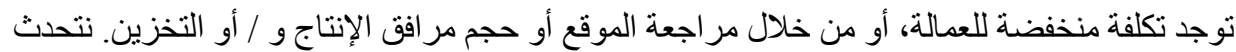

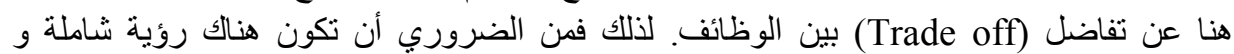
"نظمية" لهذه السلسلة من الوظائف.

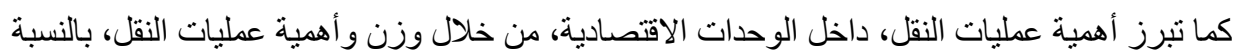

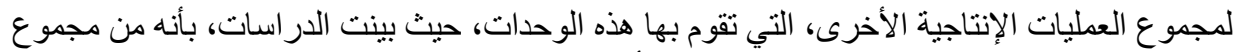
النشاطات الني تقوم بها الوحدات الاقتصأدية، نجد أنه : 
من أجل طن واحد من المواد المنتجة، يتم تحريك أو نقل 48 طن في المنوسط، من المو اد و العتاد بين مختلف أماكن العمل في الوحدة الاقتصادية.

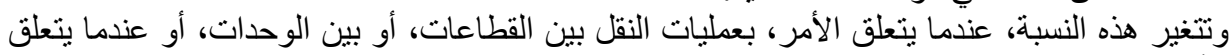

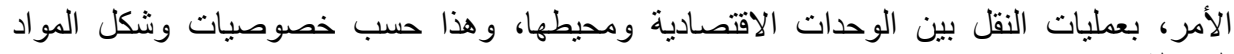
$\checkmark$ بالنسبة لصناعة الصلب والحديد مثلا، من أجل إنتاج طن واحد من الحديد

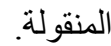
(fonte) (manipuler) بين يتم نقل وتحريك 120 و 180 طن لمختلف المو اد الأولية و العتاد.

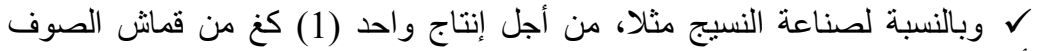

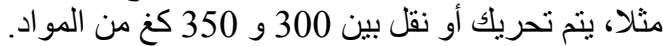

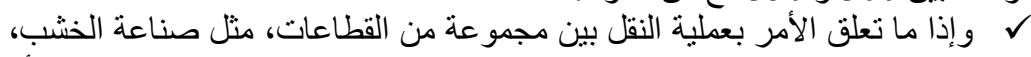

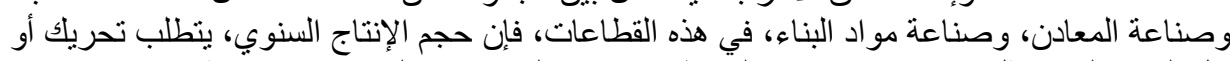

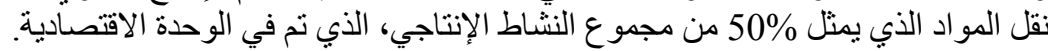

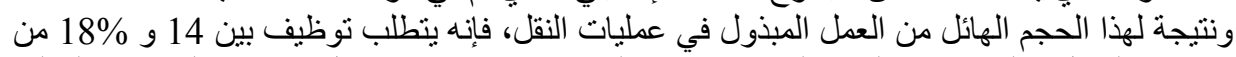

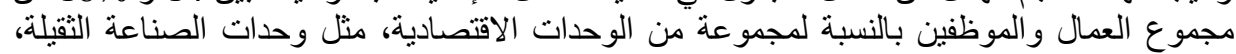
حيث نفقات النقل، تمثل نسبة 15 إلى 30\% مقابل نكاليف التسيير. كل هذه النقادية النسب، تبرز الدور الهام للالنقل، في تحقيق العملية الإنتاجية.

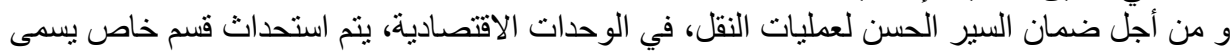
"قسم خدمات النقل"، ويكلف بمجمو عة من المهام و التي من أهمها:

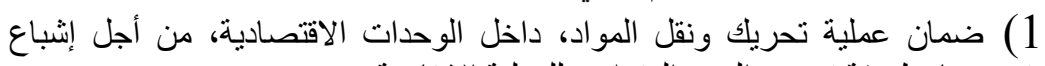
الطلب عليها، وتوزيعها بطريقة تضمن السير المنو ازن للعملية الإنتاجية

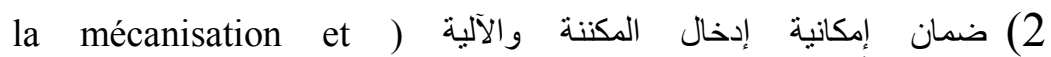

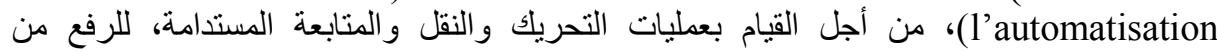
مستو اها. 3) التحسين المستدام لوسائط النقل المستعملة، وتحديث عمليات النقل، من خلال الاختيار العقلاني لوسائط عالية الفعالية و المردودية.

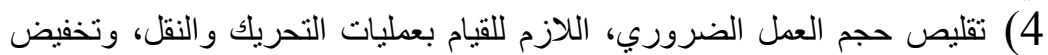
التكاليف المتعلقة بهذه العمليات. الثكل رقم 3 يبين مختلف مهام قسم خدمات النقل

شكل رقم 3: مختلف مهام "قسم خدمات النقل". 


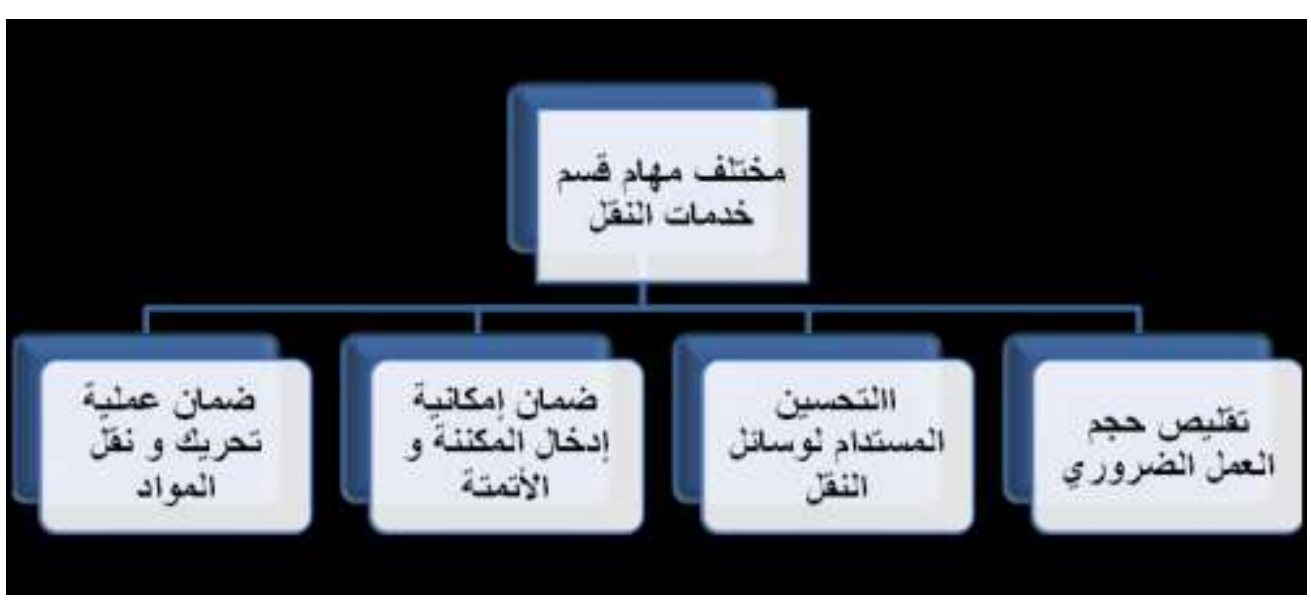

المصدر: الثكل من تصميم الباحث.

\section{5) ترتيب عمليات النقل ومعايير اختيار الوسائط.

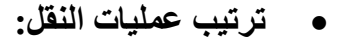

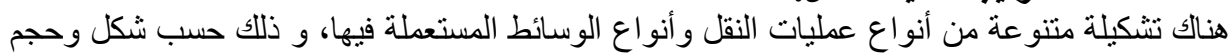

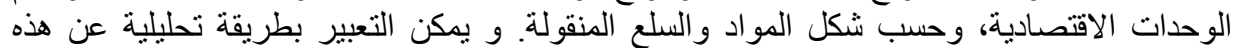
التشكيلات من خلال ترتيبها حسب معايير مختلفة:

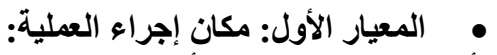
حيث يمكن أن يكون النقل، خارجيا أو داخليا.

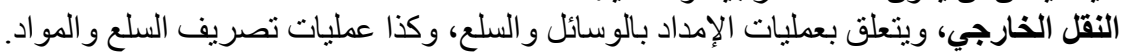

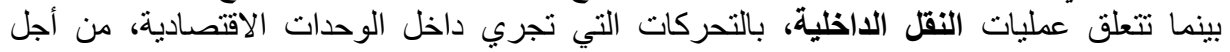
توزيعها بطريقة مثلى. تيعلى يمكن ترتيب عمليات النقل الداخلي، حسب كيفية الاستعمال، إلى النقل فوق الأرض و النقل البحري و

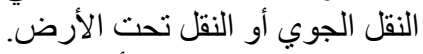

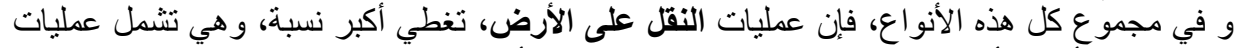

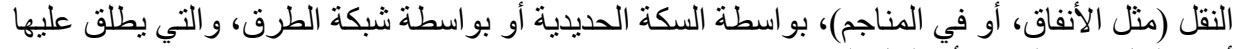
أسم، النقل عبر الطرق أو النقل البري.

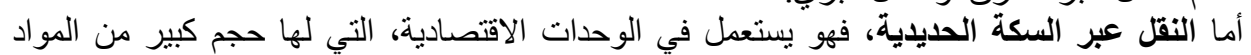

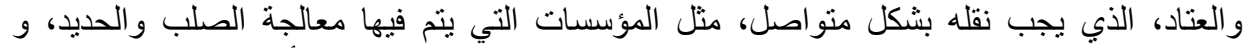

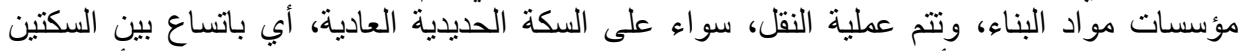

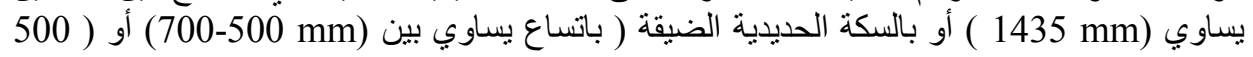
. (mm

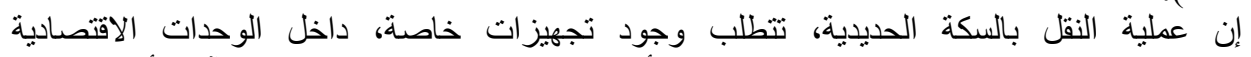

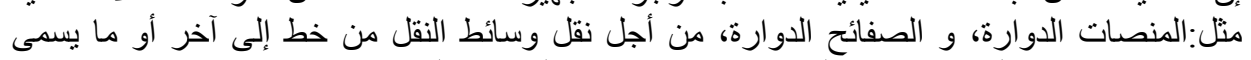
(transbordeur) إلا أنه بر غم أهميته البالغة، فإن النقل بالسكة الحديدية له مساوئ عدئ لديدة منها: 
أ. ت تتم عملية النقل عبر بعض المسالك المتعرجة و التي تفرضها طبيعة

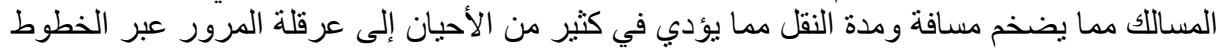

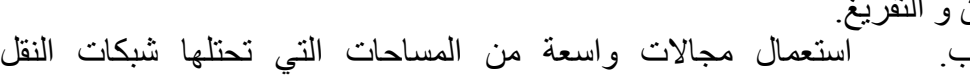
خلال عمليات الثحن و التفريغ.

ومعداتها.

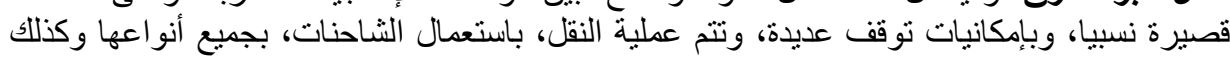

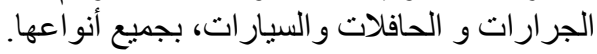
يتميز النقل عبر الطرق، بحركية كبيرة، مما يسمح بتحريك المواد التواد والسلع بسهولة، بين مختلف نقاط التوزيع وذللك عبر أقصر مسار مدكن.

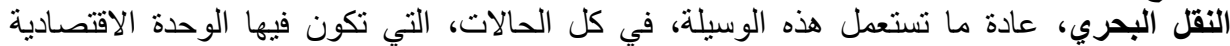

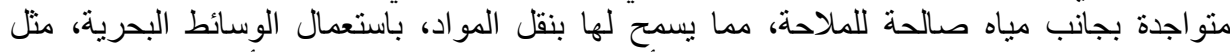

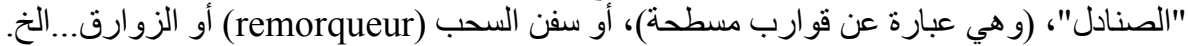

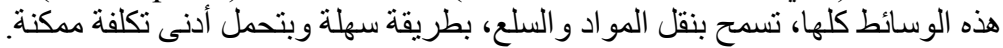

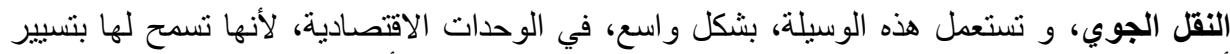

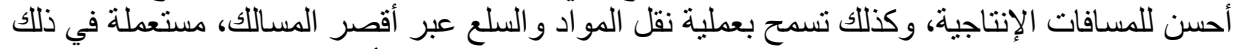

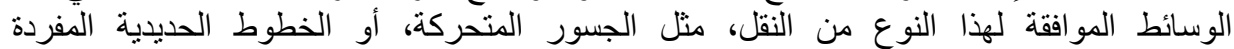
(monorail) (أو القاطر ات المتنقلة بو اسطة السكك الحديدية (funiculaire).

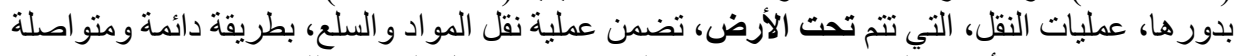

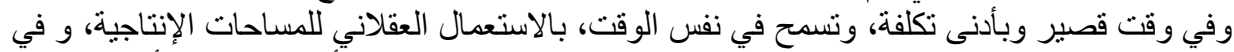

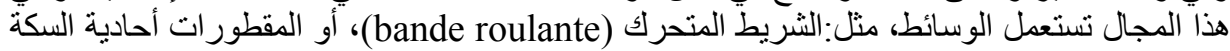

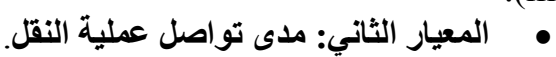

(monorail)

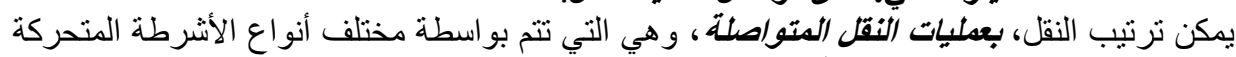

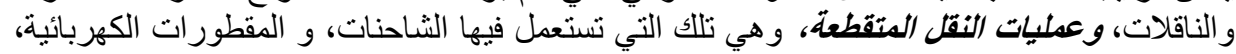
و الجسور الكهربائية.

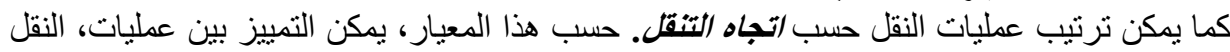

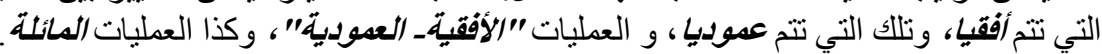

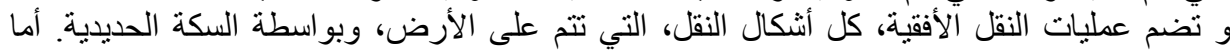

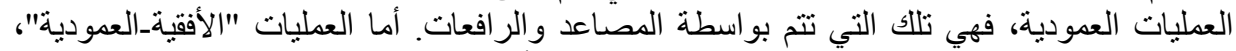

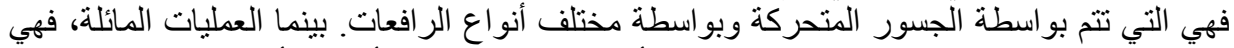

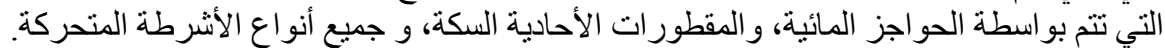

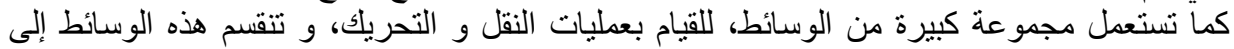

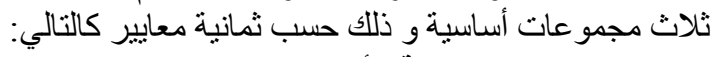
المجموعة الأولى الكي

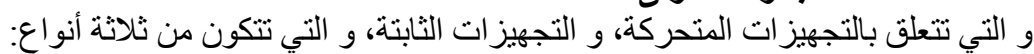

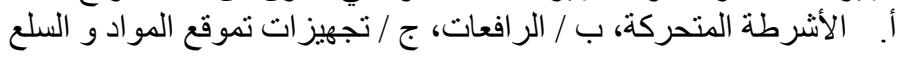

.(équipement de positionnement) المجموعة الثانية

و تتعلق بالتجهيزات المتحركة، و تحتوي على أربع فئات كالتالي: 
/ المركبات الصناعية، ب / المركبات المجهزة بمحرك، ج/ المقطورات على السكة الحديدية،

\section{المجموعة الثالثة}

د/ النقل الجوي

و تتعلق بالتجهيز ات الثابتة، و تحتوي على فئة ائة واحدة تتمنل في وسيلة النقل بالحاويات.

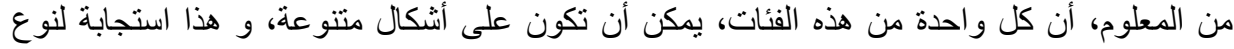

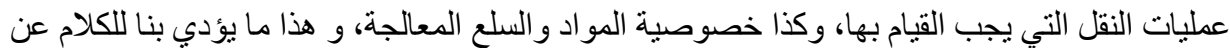
معايير اختيار التجهيز ات المستعملة في عمليات النقل و التحريك.

6) معايير اختيار التجهيزات المستعملة في عمليات النقل و التحريك.

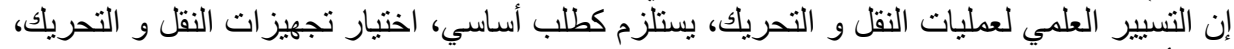

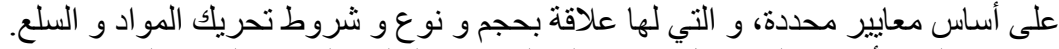

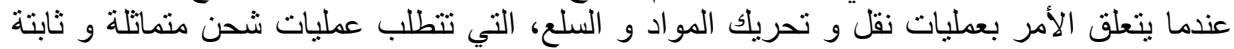

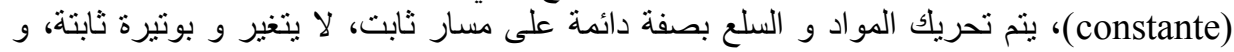
يكون مجال التصريك ثابتا.

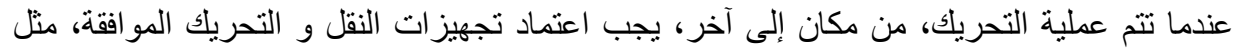

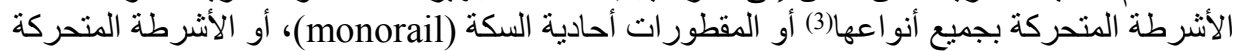

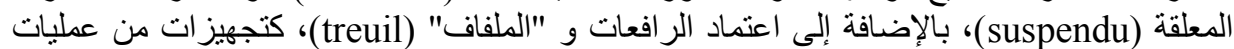
النقل في العلو، لتحريك مختلف الحمو لات، بطريقة متقطعة بين مو اقع منو اجدة في مساحة محددة، على الى مسار تحريك المو ادو السو السبع. ويتم اختيار الوسائط، في الحالة التي يكون فيها هدف التحريك، هو تحويل (transfert) الحمولات،

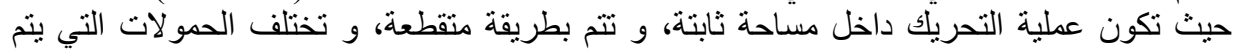

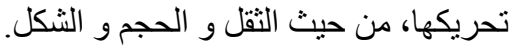
على أساس هذه المعايير، تعتمد تجهيزات النقل و التحريك، على مختلف أنواع الجسور المتحركة و الر افعات بمختلف أنو اعها.

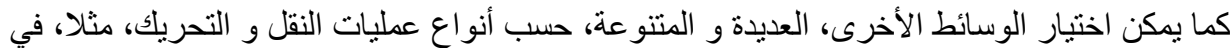

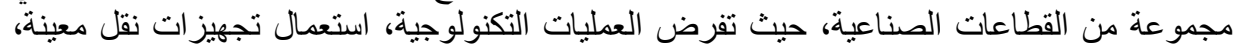

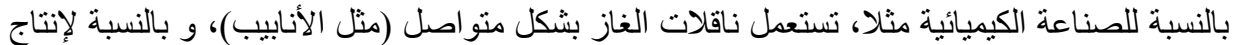

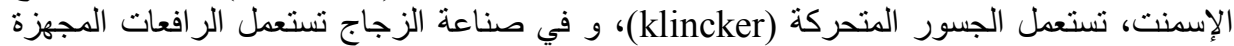

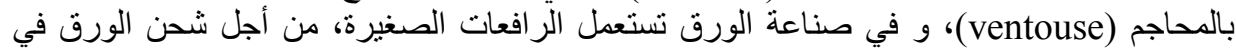
الثاحنات.

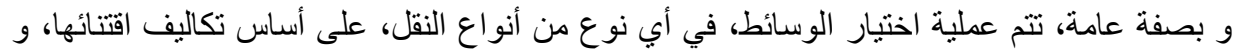

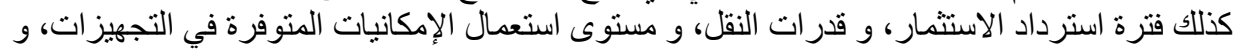

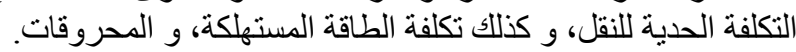

\section{القسم الثاني:التطبيقات الحديثة للنقل متعدد الوسائط}

\section{تعريف النقل متعدد الوسائط:}

يعرف النقل متعدد الوسائط، بأنه عبارة عن نقل الونل الأفراد و و المواد و و البضائع، بواسطة أكثر من وسيلة

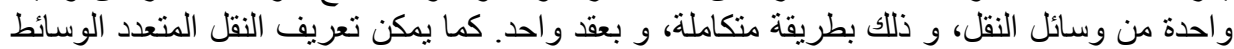

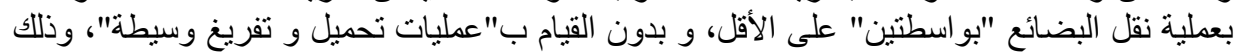

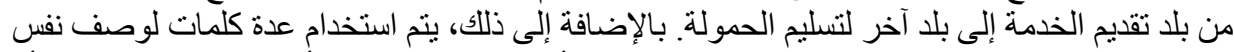

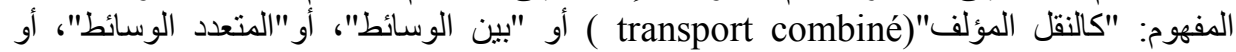

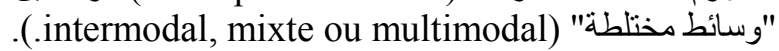


في الو اقع، في ما يخص النقل المتعدد الوسائط، يجب التمييز بين العقود المتعاقبة للنقل، الخاضعة لنظم قانونية مختلفة، حسب كل وضع، من جهة، و عقود النقل المتعدد الوسائط، التي ينم تنفيذها في إطار "عقد

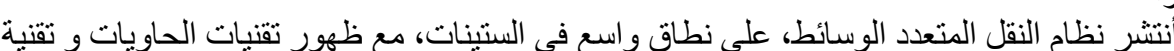

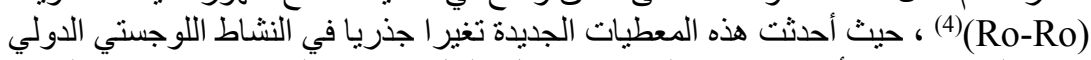

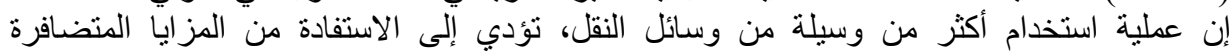

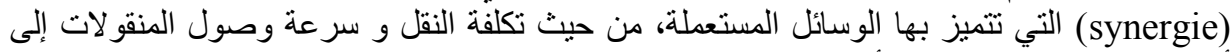
أماكنها، مع ضمان ظروف الأمن و السلامة. 1

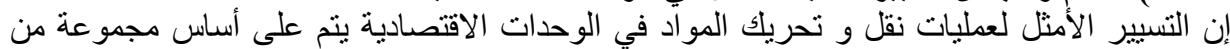

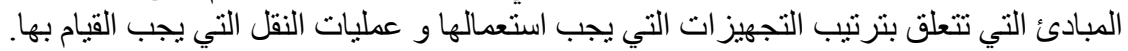

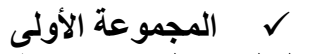

و تتعلق بالتخطيط و التنظيم، و تضم المهن الاولى العر التالية:

أ. مبدأ التخطيط: أي يجب أن تشمل عملية التخطبط، كل عمليات النقل و التحريك، التي تقوم بها الوحدة الاقتصادية

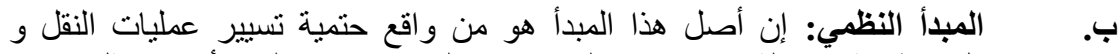

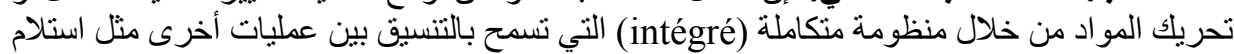

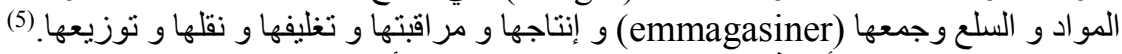

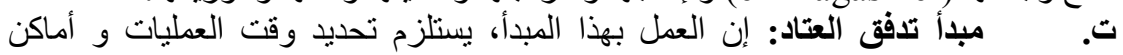

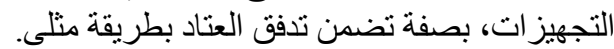

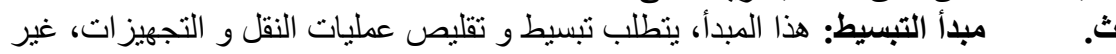
الضرورية.

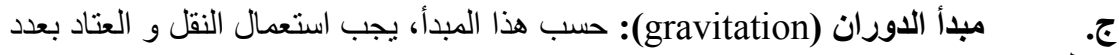
ح. من الدوران. مبأ استعمال الفضاء: تطبيق هذا المبدأ، يستلزم استعمال كل المساحات الثاغرة

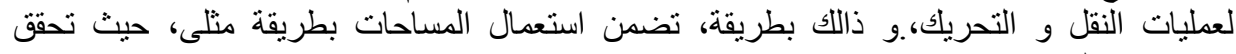
اقتصاديات الحجم.

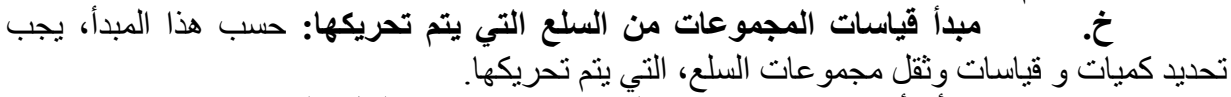

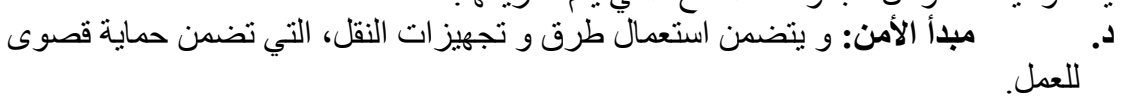
شكل رقم 4 نظم و مبادئ تسير عمليات النقل في الوحدات الاقتصادية 


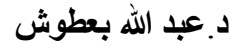

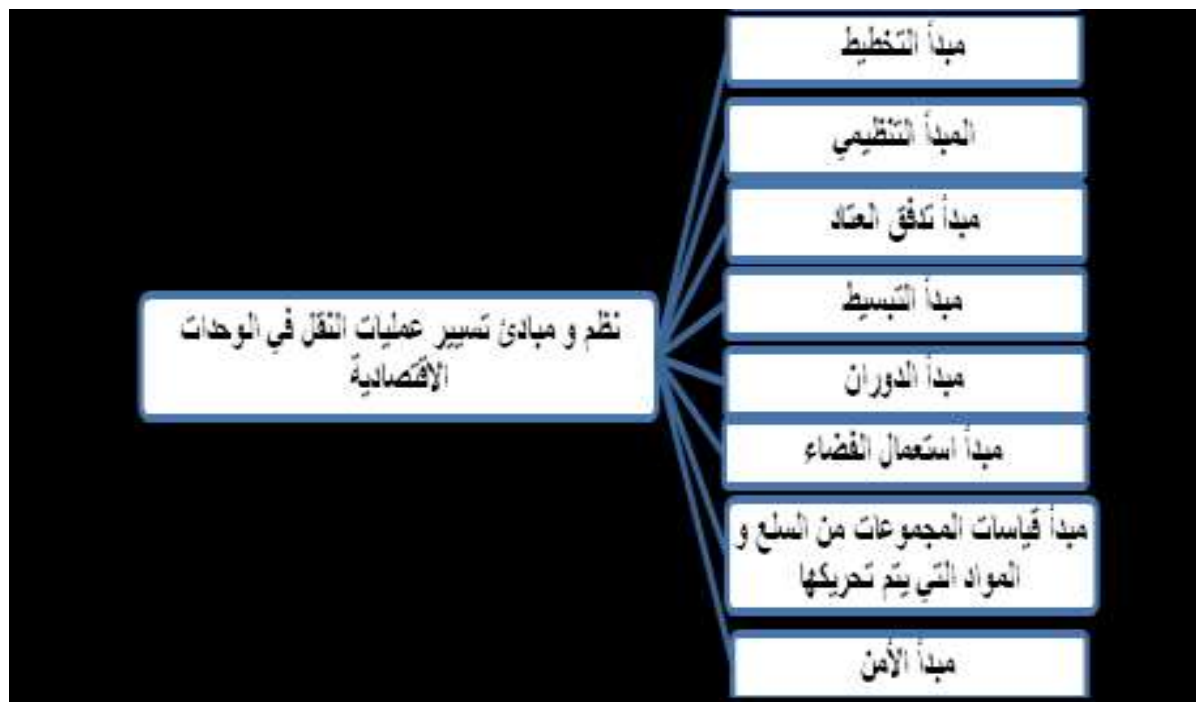

المصدر : الشكل من تصميم الباحث.

ل المجموعة الثانية من المبادئ، و تتعلق بتجهيزات النقل و التحريك:

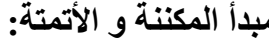

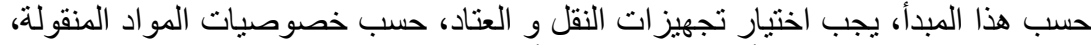
مع ضمان أعلى مستوى من المكننة و الأتمتة ،و في حدود أقل تكلفة ممكنة.

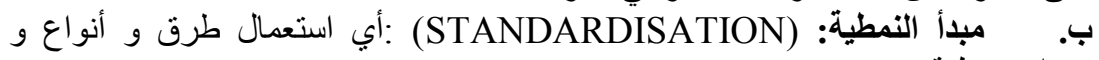

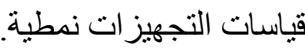

ت. ت مبذأ المرونة أو " الليونة": و يستلزم اعتماد تجهيزات النقل و التحريك، التي تكون قادرة على القيام بمجمو عة واسعة من المهام.

ث. مبدأ القدرة:capacité) و يثير إلى ضرورة تقليص النسبة، بين ثقل التجهيزات، و قدرة استخدامها (capacité utile)

ج. مبدأ التحريك: هذا المبدأ، بستلزم نوع من التسيير، الذي يجعل وسائط النقل تتحرك

ح. مبدأ الوقت الضائع: (temps mort) و يحث على تقليص "الوقت الميت" و غير باسنمر ار. المنتج، و ذلك عند القيام بعمليات النقل، و كذلإن الضك عند استعمال الوسائط.

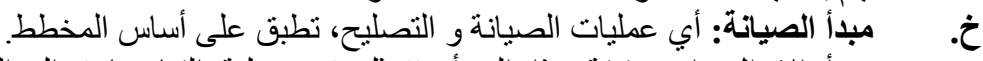

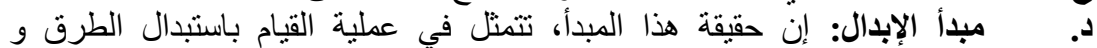

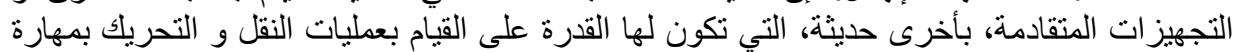

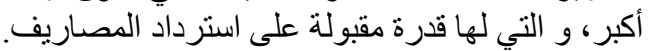

شكل رقم 5 "نظم و مبادئ تجهيزات النقل و التحريك " 


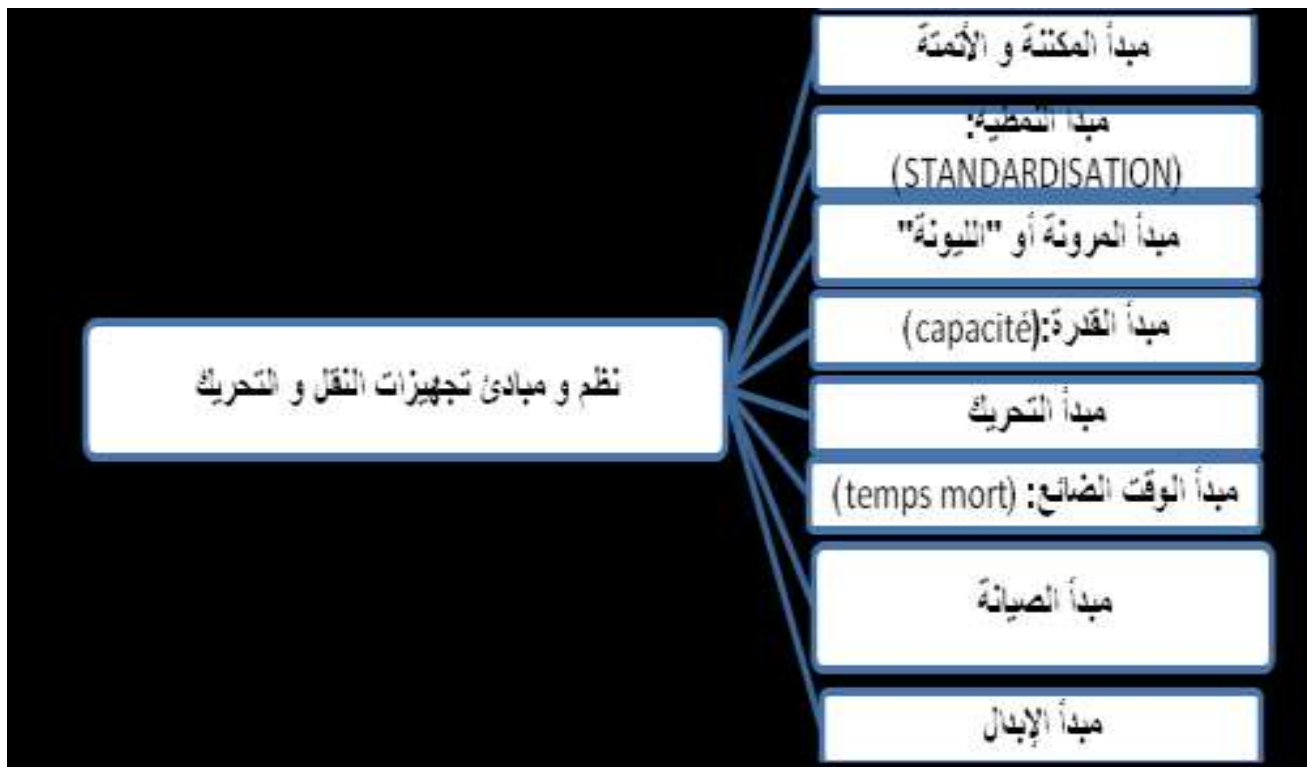

$$
\text { المصدر : الشكل من تصميم الباحث }
$$

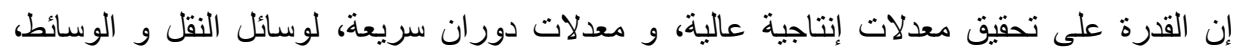

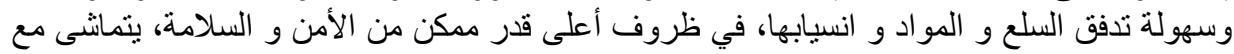

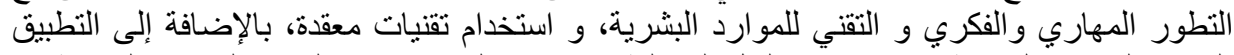

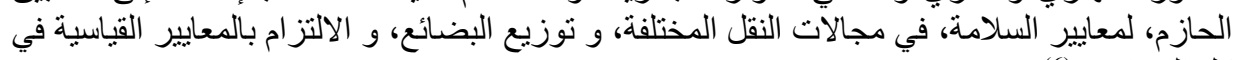
كل المجالات. (6) المعاير)

المجموعة الثالثة و تتعلق بالعمليات:(أي عمليات النقل)،.و تجمع المبادئ التالية:

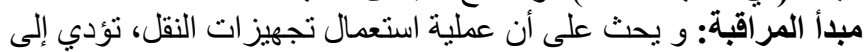

تحسين مر اقبة كل من الإنتاج و المخزون و كذا عمليات النقل و التحريك.

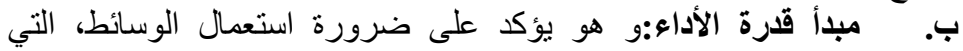

$$
\text { تضمن تحقيق كامل الطاقة الإنتاجية. }
$$

ت. ت مبدأ كفاية القدرات:efficience des performances) هذا المبدأ

يؤكد على ضرورة العمل على تثبيت نظام العمل، بوسائط النقل عند مسنوى أقل نكلفة مدكنة لكل وحدة منقولة. إن مدى استعمال هذه المبادئ يجب أن يكون على أساس التحسين الأمثل لنظم تسبير النقل و التحريك و

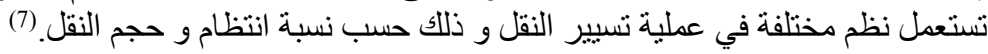

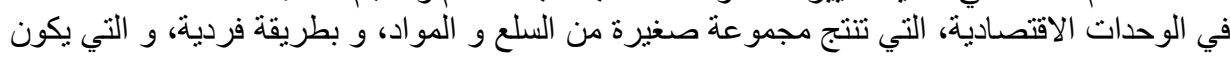

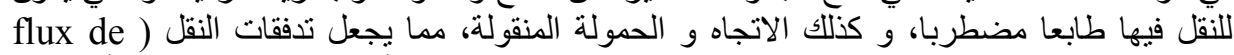
(transport 
و في المقابل، في الوحدات الاقتصادية المنتجة بحجم كبير، حيث تتسم تدفقات النقل بالاستقرار، ينم

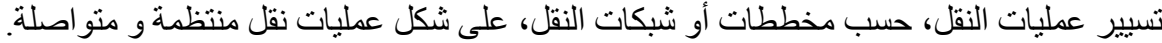

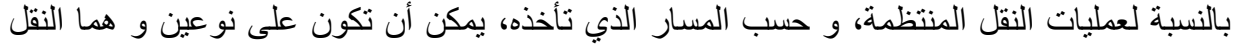
على شكل البندول (transport pendulaire) و النقل الدائري (circulaire).

تجري عمليات النقل من الصنف "البندول"، عندما يتم تحريك المواد و والسلع، باستعمال الوسائط بين

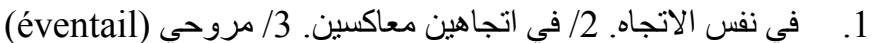

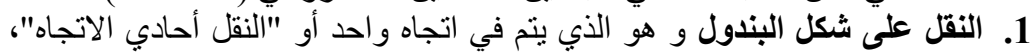

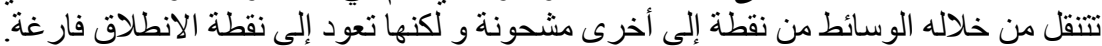

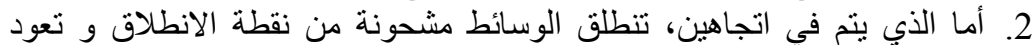

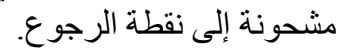
3. النقل المروحي و هو الذي تتحرك فيه الوسائط من نقطة الانطلاق إلى نقاط عديدة و ذللك سواء في اتجاه واحد أو في اتجاهين متعاكسين. الثكل التالي يبين مختلف أنو اع اعن النقل المروحي.

شكل رقم 6 مسار تدفق النقل المروحي و مختلف العمليات المطبقة.

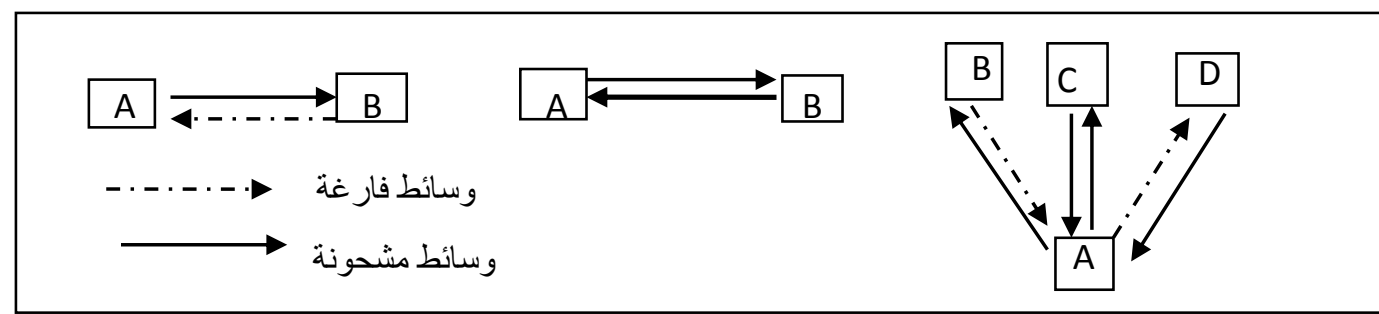

المصدر : الثكل من تصميم الباحث.

يبين الثكل رقم 5 أنه في العملية الأولى، تغادر الوسائط مشحونة ثم تعود فار غة، ثم العملية الثانية، التي التي

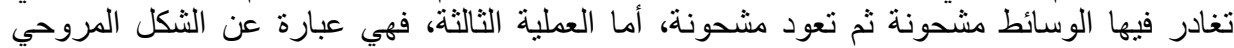

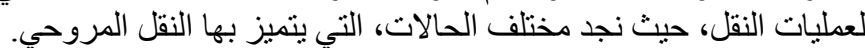

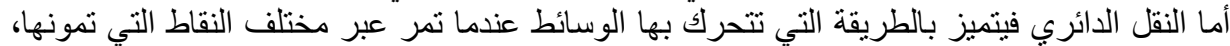

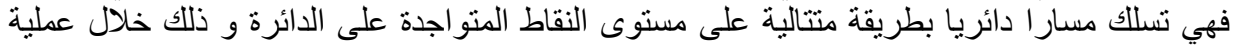
تسليم أو استلام الثحنات ثم تعود إلى نقطة الانطلاق التياق

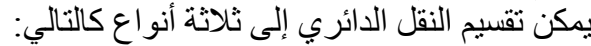

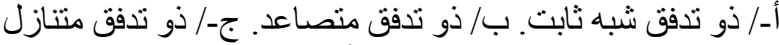

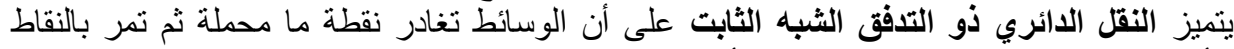

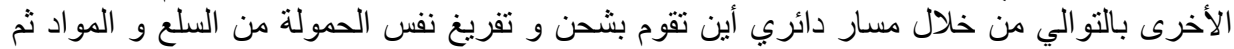

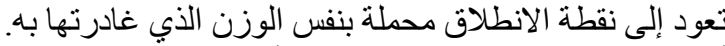

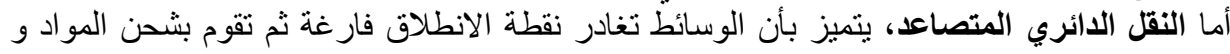

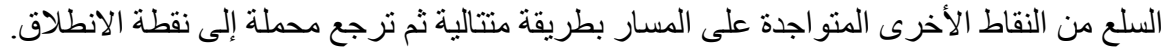

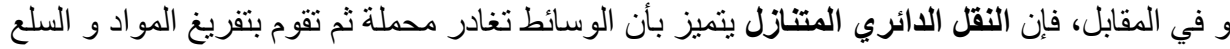

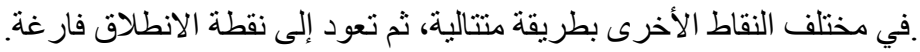
الثكل 7 أنواع النقل الدائري 


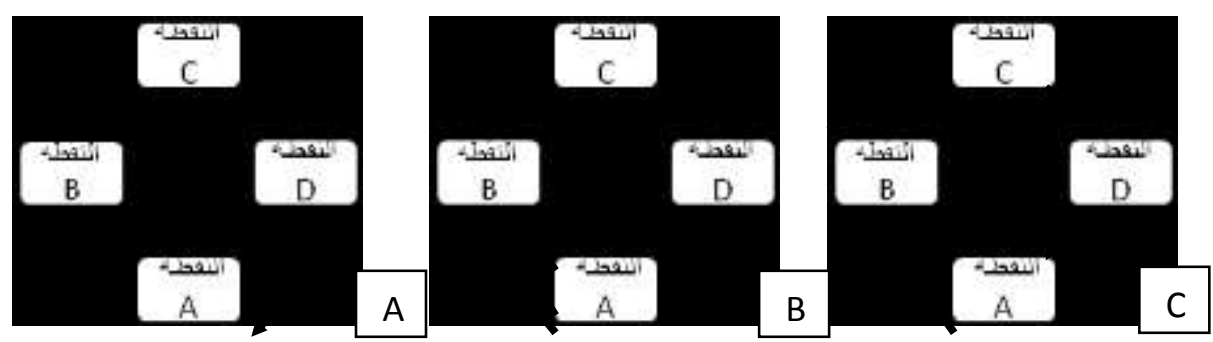

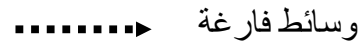

$\longrightarrow \quad$ وسائط محملة

المصدر : الثكل من تصميم الباحث

الثكل6، يبين مسار النقل، بين أماكن أو نقاط مختلفة، و أنواع النقل الدائري، حيث نجد مثنا، الثكل الثنل

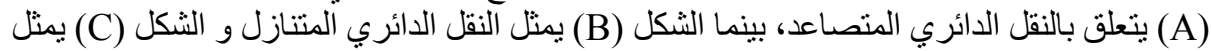

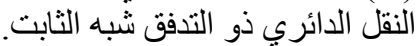

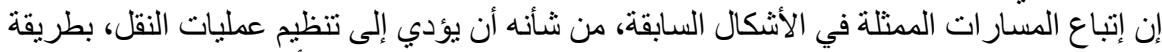

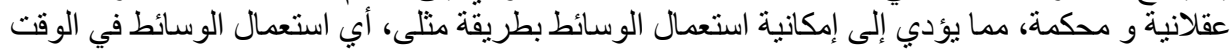

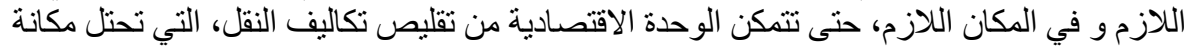
كبيرة في عملية ترشيد مجموع نفقات التسيير بصفة التحة عامة.

2 أ. أل ظهور تقنيات الحاويات:

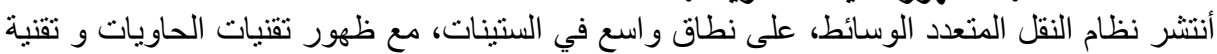
(Ro-Ro)

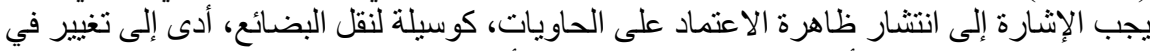

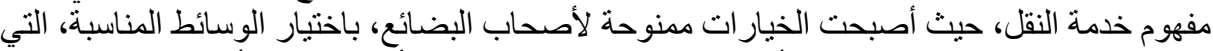

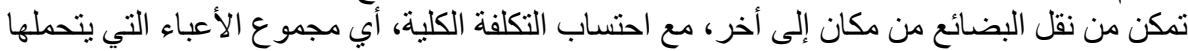

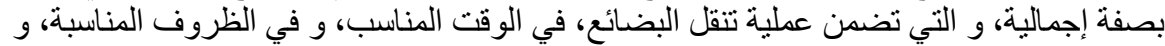

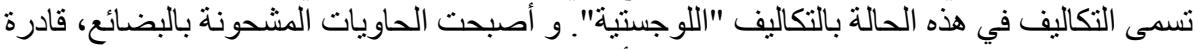

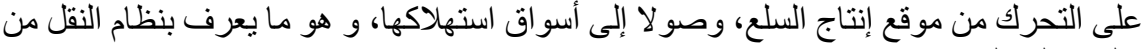

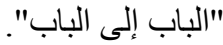

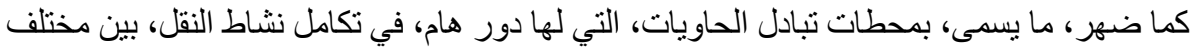

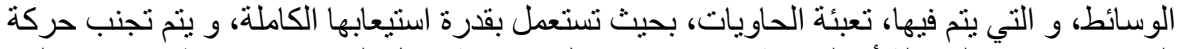

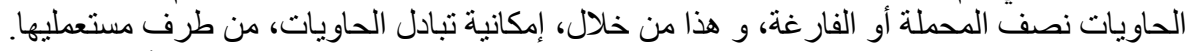

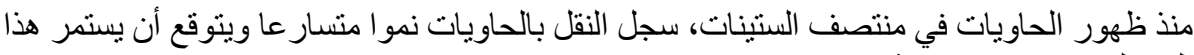

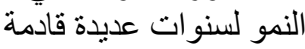

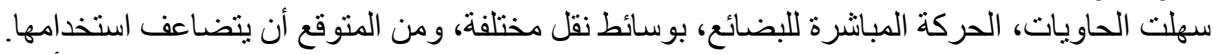

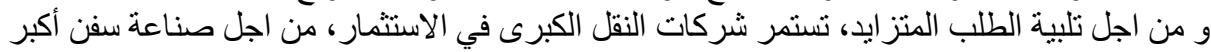

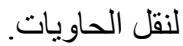

كما يسجل، دخول وخروج الحاويات، في المو انئ في جميع أنحاء العالم، زيادة من صفر في في عام 1960 في 1965 إلى 225.300 .000 في عام 2000. و تضاعفت حركة الحاويات في عام 2010، حيث قاربت في عاد 500 في 


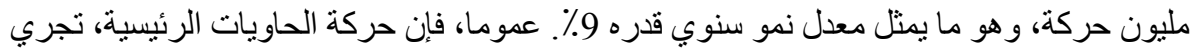

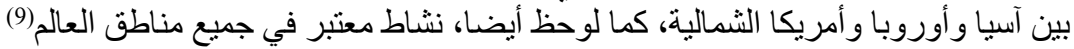

\section{ب. تكنولوجيا المعلومات والاتصالات:.}

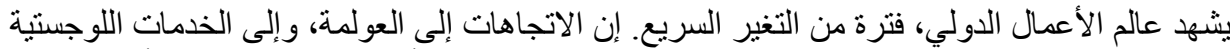

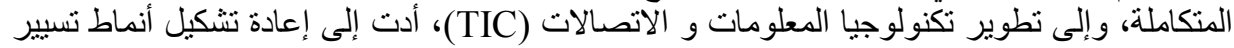

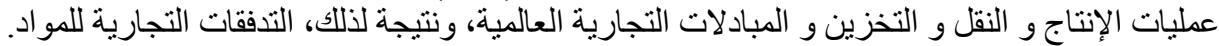

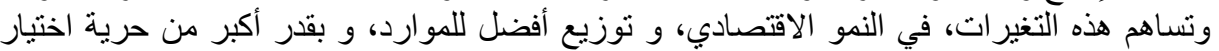

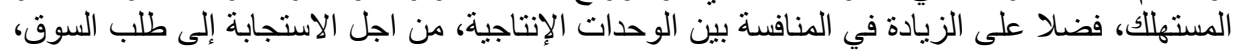

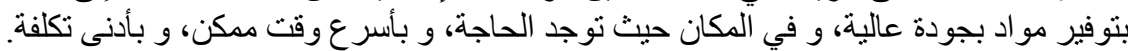

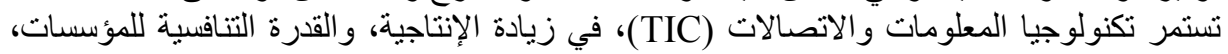

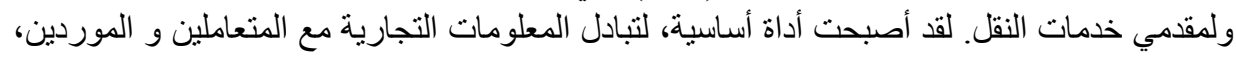

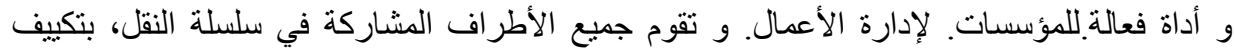

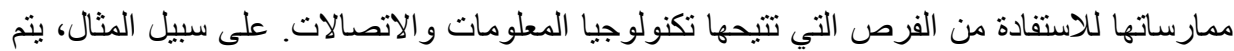

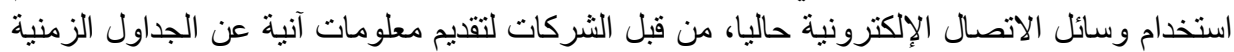

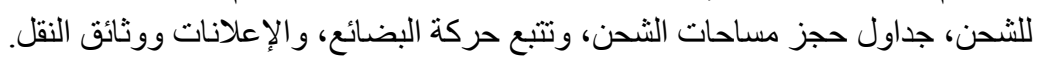

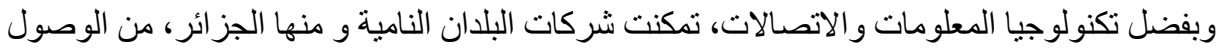

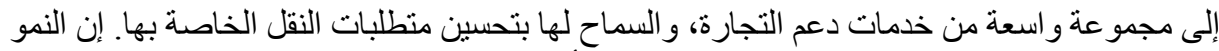

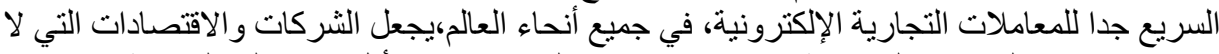

تعتمد ممارسات التجارة الإكترونية قد تفقد حصنها في السوق وتصنيح ألحاء القل قدرة على المنافسة.

\section{ج. النقل المتعدد الوسائط للبضائع: تطوير التطبيقات ""الثحن الإكتروني" ".}

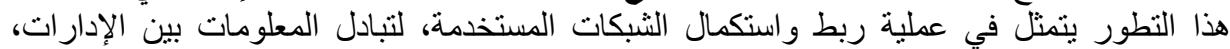

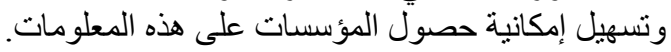

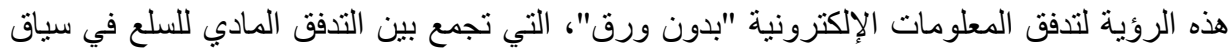

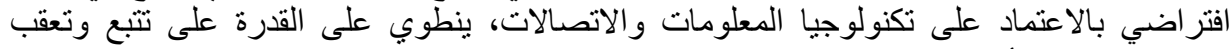

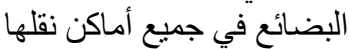
كما تمكن عمليات الثحن الإلكتروني، من تبسيط تبادل المعلومات عن البضائع و النقل، مما بسمح،

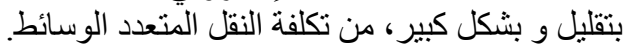

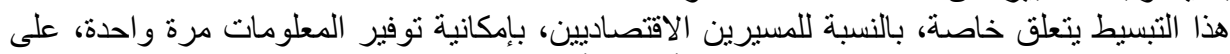

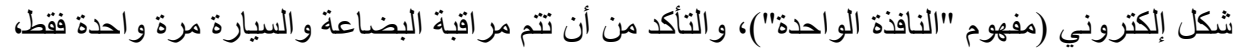

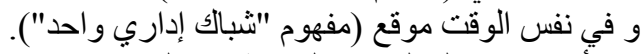

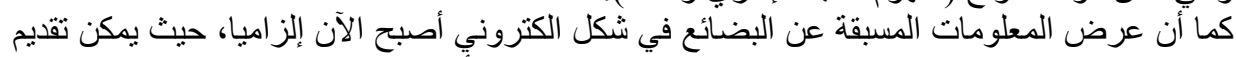

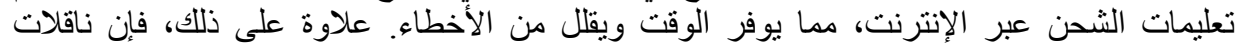

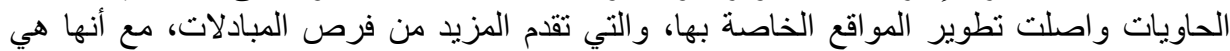

الأخرى تتو اصل مع البو ابات الإلكترونية الثناثة.

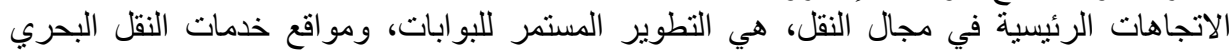

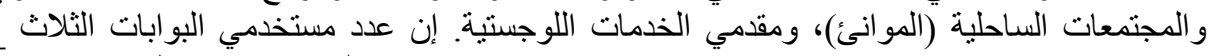

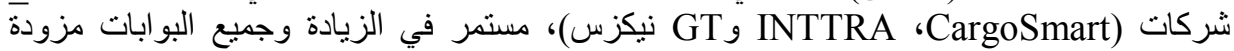
بالوظائف التي تسمح للثاحنين توفير المعلومات إلكترونيا. 
كما أطلقت هوتثشيسون بورت القابضة( Hutchison Port Holding)، مشغل المحطات العملاقة

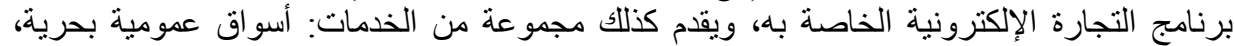

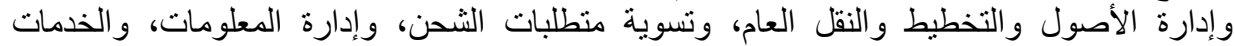

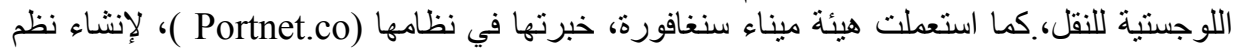
مجموعة الميناء في داليان (الصين) وسياتل (الو لايات المتحدة) وجنوب أفريقيا.

\section{د. الخدمات اللوجستية المادية الصديقة للبيئة}

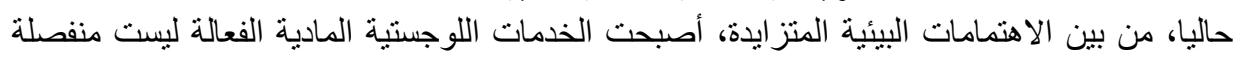

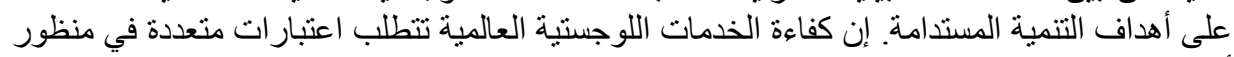

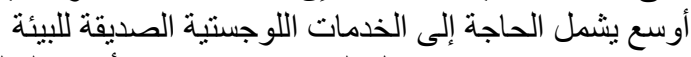

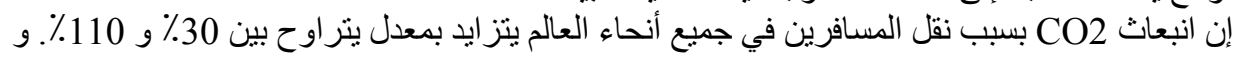

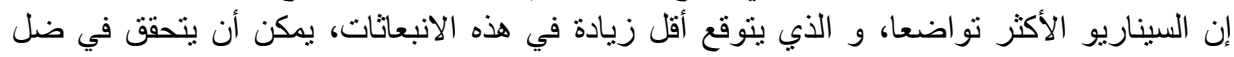

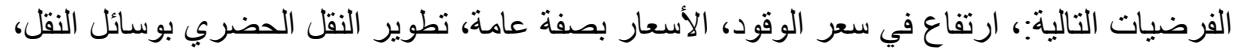

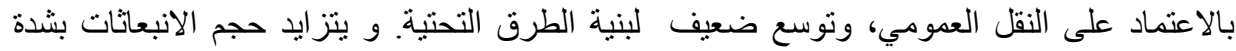

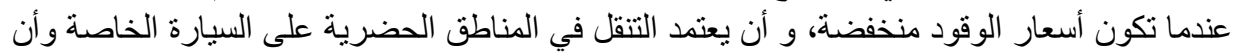

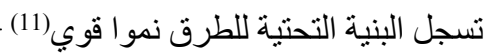

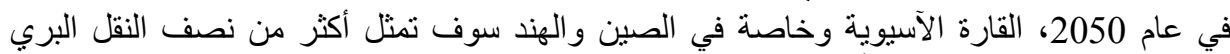

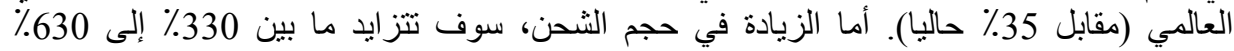

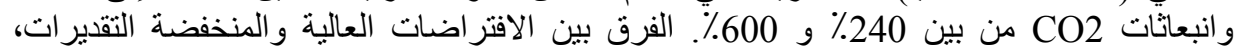

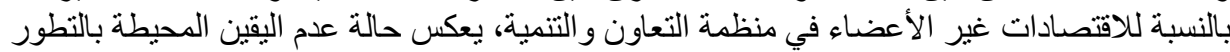

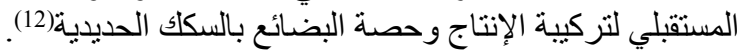

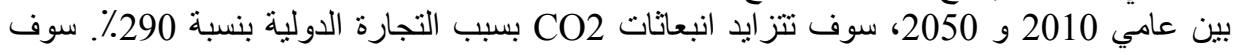

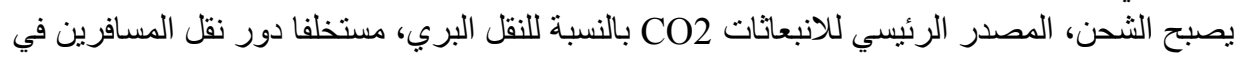

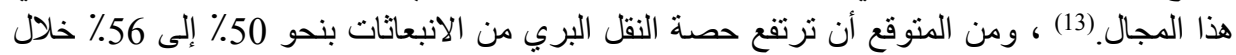
هذه الفترة(14).

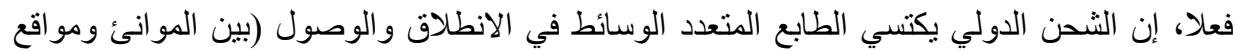

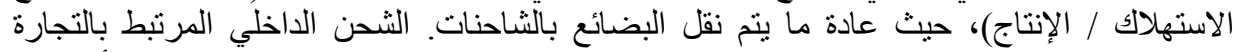

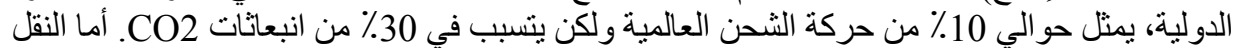

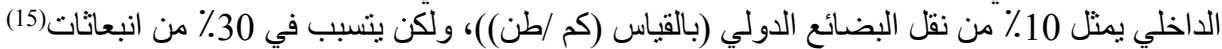

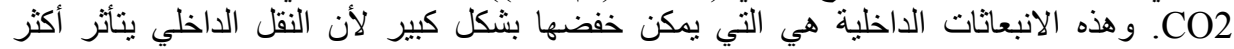

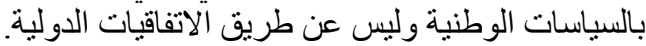

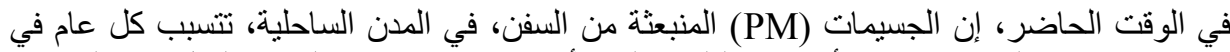

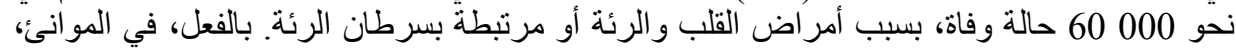

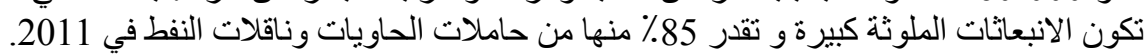

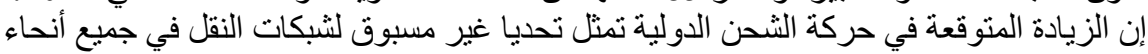

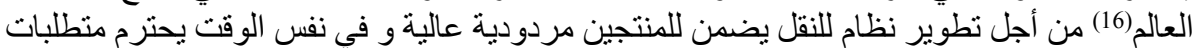

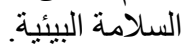

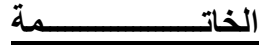

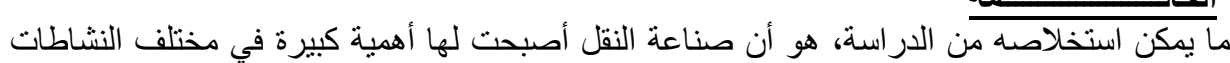
الاجتماعية و الاقتصادية، و خاصة فيما يخص عمليات تخطيط و تسير النشاط الإنتاجي للوحدات اللنات

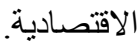


و لقطاع النقل المتعدد الوسائط، دور أساسي، في تتمية العديد من القطاعات الأخرى الاجتماعية

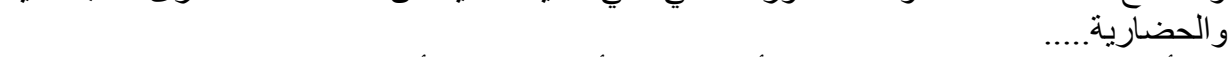
كما أن تطوير النقل المتعدد الوسائط، أصبح يشكل أحد الوسائل الأساسية، في نسج علاقات مستدامة،

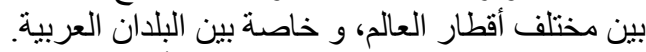

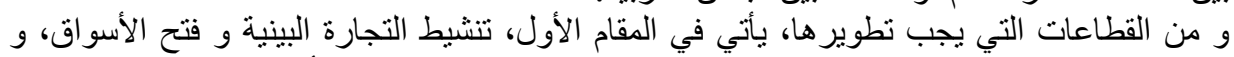

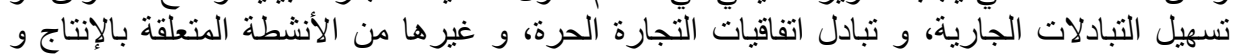

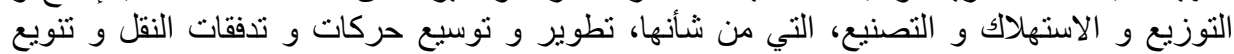

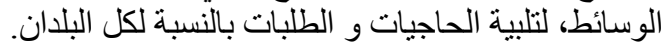

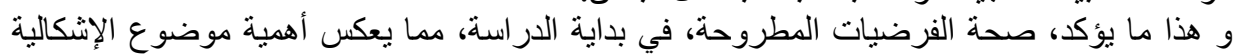
المقتر ح للار اسؤة. يمكن استخلاص الملاحظات التالية:

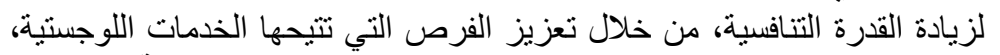

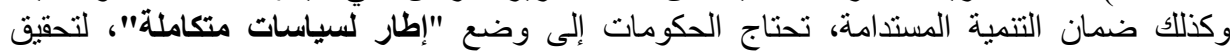
الأهداف الاجتماعية و الاقتصادية على نطاق أوسع.

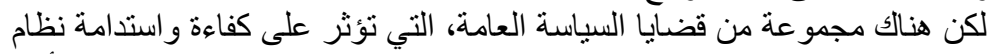

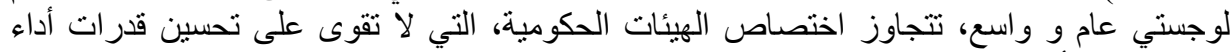

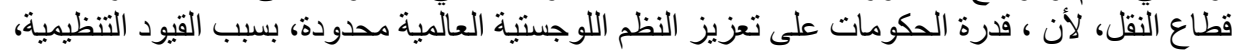

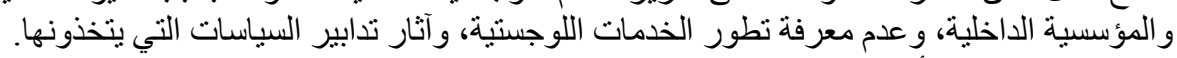

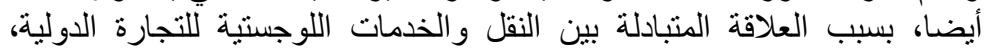

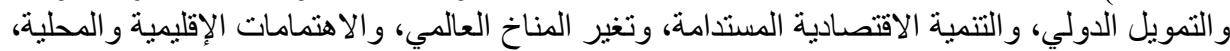

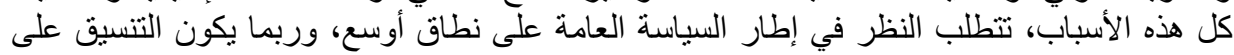

لكي تكون تنافسية ، يجب على البلدان و الثركات، الوصول حتما إلى وسائل النقل الصعبد الدولي.

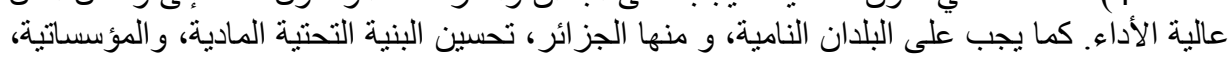
و القانونية، لخلق الظروف المواتية، لتطوير خدمات النقل، التي من شأنها تعزيز الاستثمار والتجارة التهارة

تنفيذ تدابير تسهيل عمليات النقل والتجارة، هو في صميم المداو لات الدولية الحالية،

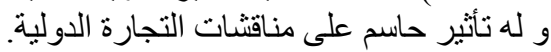

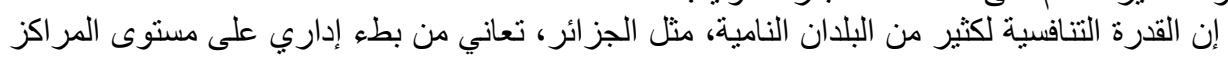

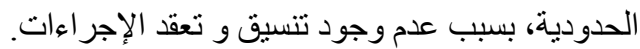
إن الإجر اءات، التي من شانها تسهيل المعاملات التجاءرية، أتباء أصبحت بالنسبة للبلدان النامية، أداة أساسية للحد من تكاليف المعاملات.

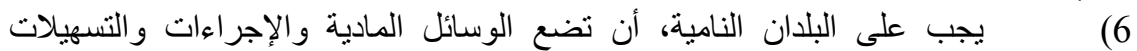
اللازمة، لتقو افق مع القو اعد الجديدة. كما أن الامتثال لمتطلبات الأمن، من شأنه تسريع الإجراءات الجمركية، ولنات تسهيل عملية تسليم البضائع

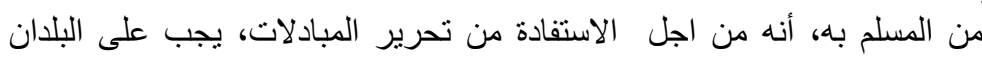

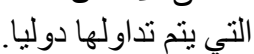

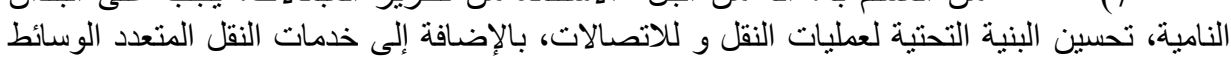

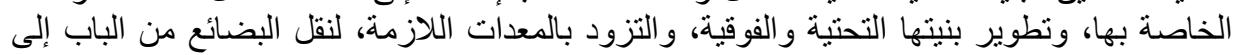

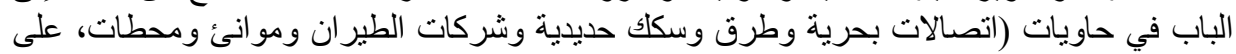


وجه الخصوص). بما في ذللك القطاع الخاص، فهو أيضا يشارك بصورة متز ايدة، في عملية استغلال

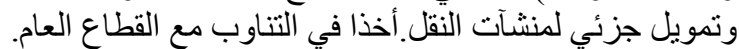

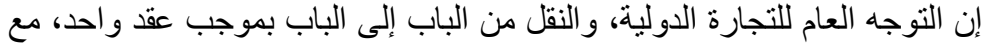

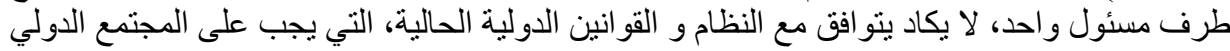

توحيدها، لكي يستمر النقل المتعدد الوسائط في التطور.

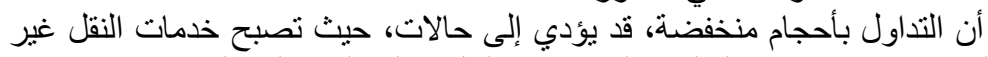

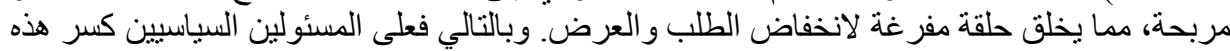

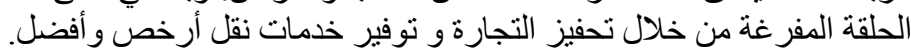

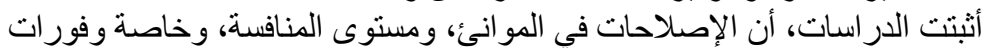

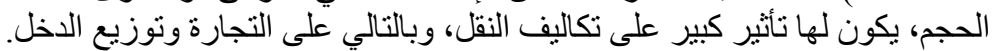

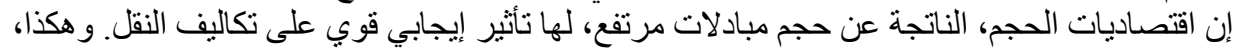

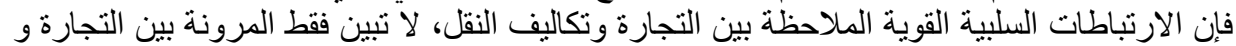

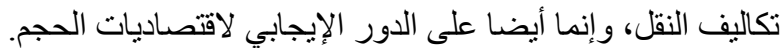

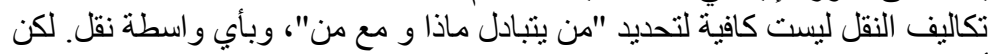

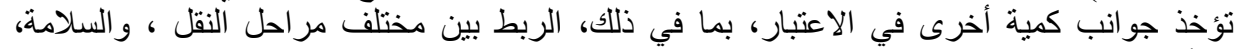

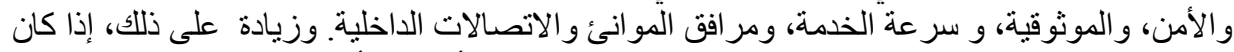

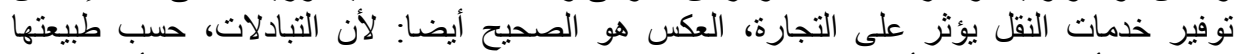

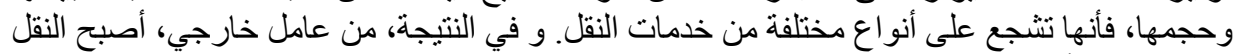

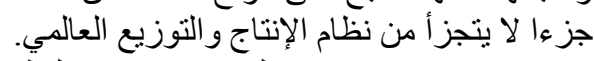

يجب السعي باستمرار لنظام نقل أكثر كفاءة عن طريق تحسين تكوين الثبكات

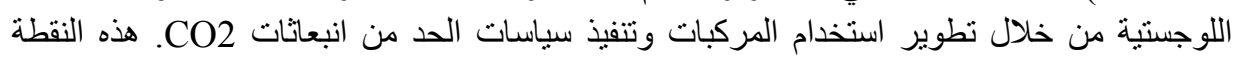

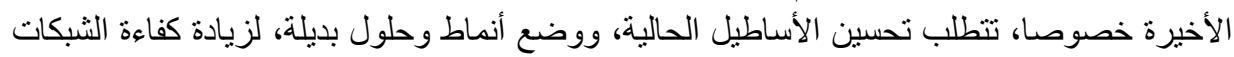

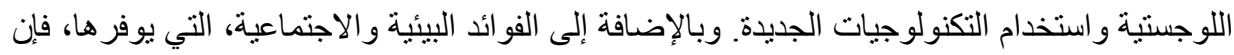

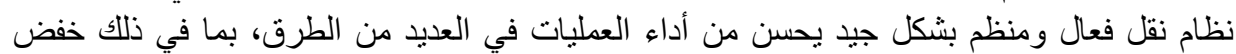

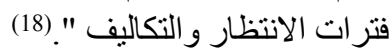

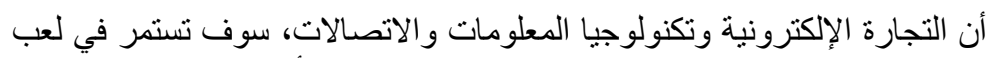

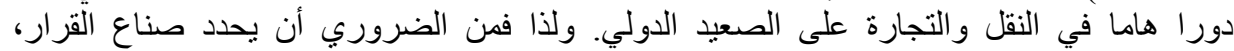

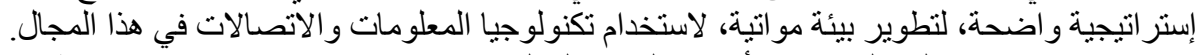

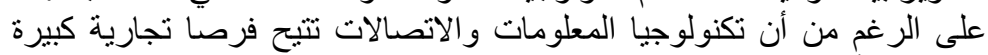

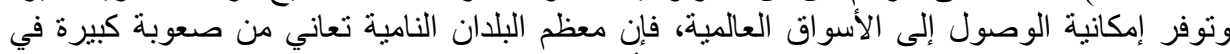

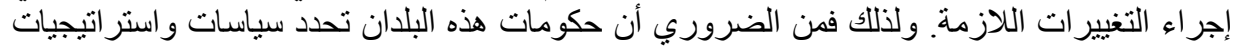

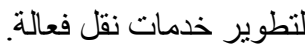

قائمة المراجع: - ماتع

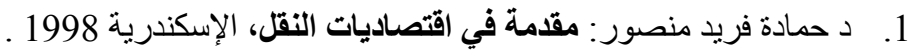

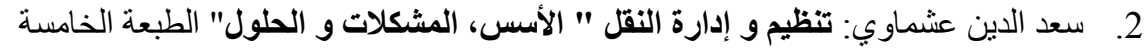

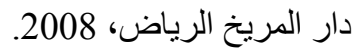

3. شريف محمد ماهر : تخطيط النقل و سياسته، الدار الجامعية الإسكندرية 2006.

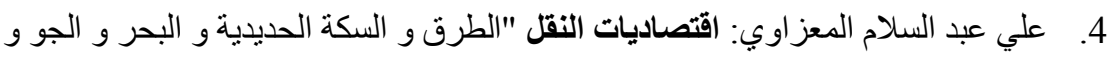

الأنابيب"دار السلام، القاهرة، 2006

5. ع بعطوش: محاضرات في اقتصاد النقل مطبو عة غير منشورة 2000.

109 


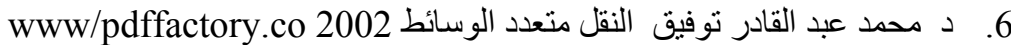
المو اقع الإلكتثرونية:

7. Bauchet $\mathrm{P}$ l'économie du transport international de marchandises Economica, Paris, 1982

8. Du Jonchay I, Murfy M et Serraz F les grands transports mondiaux : coll Bordas Paris 1978.

9. Du page RP : l'action commerciale internationale : col Université et techniques, Dunod 1976.

10. Gaither $\mathrm{N}$ l'entreprise et la gestion des opérations, éditions HRW, Montréal, 1983

11. WolkowitscK M Géographie des transports, Armand colin, Paris 1982.

12. Le Bulletin des transports de la CNUCED de février 2003 présente une analyse des possibilités de transaction offertes par les sites Web des 20 premiers transporteurs de conteneurs _ UNCTAD/WEB/TLOG/2003/1, p. 8.

13. CNUCED Multimodal transport: The feasibility of an international legal instrument

14. https://www.google.dz/search?client=opera\&q=applications + modernes $+\mathrm{du}+$ transport+multimodal. UNCTAD/SDTE/TLB/MISC/2004/4 31 décembre 2004

15. UNCTAD/SDTE/TLB/2003/1, 13 janvier 2003, p. 4.

16. notre-planete.info, http://www.notre-planete.info/actualites/4211augmentation-transport-marchandises-CO217 février 2015 ,

notre- (José Viegas, Secrétaire Général du Forum International des Transports planete.info, $\quad$ http://www.notre-planete.info/actualites/4211-augmentation-

1 transport-marchandises-CO2

$$
\begin{aligned}
& \text { الـهو (مش: } \\
& \text { 1-يمكن إعطاء تفسير أكثر لهذه الوظائف و لكن مجال المقالة لا يمكننا من ذاللك. }
\end{aligned}
$$

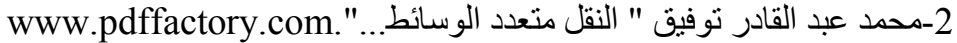

$$
\begin{aligned}
& \text { 3-توجد أنواع مختلفة من الأشرطة منها الأشرطة المرنكزة على الثئط البكر ات(galets) و منها الأشرطة } \\
& \text { المائلة . الخ. }
\end{aligned}
$$

4-Appelé Ro-Ro (de l'anglais Roll-On/Roll-Off), cette technique permet à un véhicule routier d'entrer/de sortir par ses propres moyens d'un navire, ou dans le cas de la route roulante, d'un train. (Voir un navire roulier)

$$
\begin{aligned}
& \text { 5- أنضر تعريف الخدمة اللوجستية,المحور الثالث من القسم الأول ص } 4 \\
& \text { 6-محمد عبد القادر توفيق النقل متعدد الوسائط....... }
\end{aligned}
$$

www/pdffactory.com 


$$
\text { 7- أنضر في ذاللك تعريف الخدمة اللوجتسة ص4 }
$$

8-Appelé Ro-Ro (de l'anglais Roll-On/Roll-Off), cette technique permet à un véhicule routier d'entrer/de sortir par ses propres moyens d'un navire, ou dans le cas de la route roulante, d'un train. (Voir un navire roulier)

9-Selon une étude du secrétariat de la CNUCED Multimodal transport: The feasibility of an international legal instrument,UNCTAD/SDTE/TLB/2003/1, 13 janvier 2003, p. 4.

10-Le Bulletin des transports de la CNUCED de février 2003 présente une analyse des possibilités de transaction offertes par les sites Web des 20 premiers transporteurs de conteneurs _UNCTAD/WEB/TLOG/2003/1, p. 8.

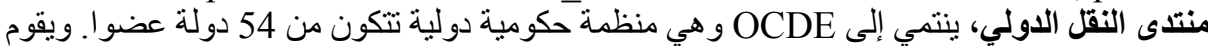

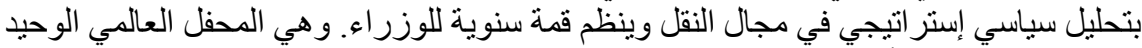

$$
\begin{aligned}
& \text { المكلف لتطوير كافة أثكال سياسات النقل في النقل }
\end{aligned}
$$

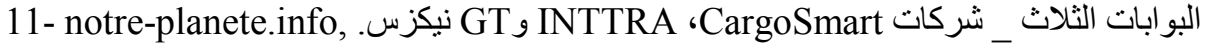
http://www.notre-planete.info/actualites/4211-augmentation-transportfévrier 2015,17 marchandises-CO2

$$
\text { 13 12 13-نفس المرجس المرجع رقم (7) المرجع رقم (7) }
$$

16-José Viegas, Secrétaire Général du Forum International des Transports ( notre-planete.info, http://www.notre-planete.info/actualites/4211augmentation-transport-marchandises-CO217 février 2015,) 17-https://www.google.dz/search?client=opera\&q=applications+modernes + du + transport + multimodal. UNCTAD/SDTE/TLB/MISC/2004/4 31 décembre 2004 